\title{
Flotation Performance, Structure-Activity Relationship and Adsorption Mechanism of O-Isopropyl-N-Ethyl Thionocarbamate Collector for Elemental Sulfur in a High-Sulfur Residue
}

\author{
Guiqing Liu ${ }^{1,2}$, Bangsheng Zhang ${ }^{2}$, Zhonglin Dong ${ }^{3, *}$, Fan Zhang ${ }^{2}$, Fang Wang ${ }^{2}$, Tao Jiang ${ }^{3}$ and Bin $\mathrm{Xu}^{3, *}$ \\ 1 School of Metallurgy, Northeastern University, Shenyang 110819, China; Charles_liu32@163.com \\ 2 Jiangsu BGRIMM Metal Recycling Science \& Technology Co. Ltd., Xuzhou 221121, China; \\ zbsvictory@163.com (B.Z.); bkyzhangfan@126.com (F.Z.); wangfang224444@126.com (F.W.) \\ 3 School of Minerals Processing and Bioengineering, Central South University, Changsha 410000, China; \\ jiangtao@csu.edu.cn \\ * Correspondence: dongzhonglincsu@csu.edu.cn (Z.D.); xubincsu@csu.edu.cn (B.X.); \\ Tel.: +86-183-7315-0200 (Z.D.); +86-150-8493-3770 (B.X.)
}

Citation: Liu, G.; Zhang, B.; Dong, Z.; Zhang, F.; Wang, F.; Jiang, T.; Xu, B Flotation Performance, StructureActivity Relationship and Adsorption Mechanism of O-Isopropyl-N-Ethyl

Thionocarbamate Collector for Elemental Sulfur in a High-Sulfur Residue. Metals 2021, 11, 727. https://doi.org/10.3390/met 11050727

Academic Editors: Ilhwan Park and Anna H. Kaksonen

Received: 11 April 2021

Accepted: 25 April 2021

Published: 28 April 2021

Publisher's Note: MDPI stays neutral with regard to jurisdictional claims in published maps and institutional affiliations.

Copyright: (c) 2021 by the authors. Licensee MDPI, Basel, Switzerland. This article is an open access article distributed under the terms and conditions of the Creative Commons Attribution (CC BY) license (https:/ creativecommons.org/licenses/by/ $4.0 /)$.

\begin{abstract}
O-isopropyl-N-ethyl thionocarbamate (IPETC) collector was used to selectively recover elemental sulfur from a high-sulfur residue, and its flotation performance, structure-property relationship and adsorption mechanism to elemental sulfur were studied. The raw ore flotation test showed that IPETC displayed superior flotation performance to the elemental sulfur compared with sodium ethyl xanthate (SEX) and ammonium dibutyl dithiophosphate (ADDTP) collectors. Pure mineral flotation and adsorption experiments further demonstrated that among the three collectors, IPETC had the strongest collecting power and the optimum selectivity towards elemental sulfur. The structure-property relationship research based on density functional theory (DFT) calculation supported the above conclusion. The adsorption mechanism analysis manifested that IPETC adsorption on elemental sulfur surface was a chemical process by separately generating normal covalent bond between carbonyl $\mathrm{S}$ atom and $\mathrm{S}$ atom and a backdonation covalent bond between $\mathrm{O}$ atom and $\mathrm{S}$ atom, which was confirmed by the FTIR spectrum analysis result. IPETC exhibits excellent collecting ability and selectivity for elemental sulfur and therefore it has bright application prospects.
\end{abstract}

Keywords: O-isopropyl-N-ethyl thionocarbamate (IPETC); elemental sulfur; flotation performance; structure-property relationship; adsorption mechanism

\section{Introduction}

Elemental sulfur is an important chemical material and has been widely used for producing sulfuric acid and other products such as fertilizers, matches, food preservation agents, carbon disulfide, cement, gun powder, surfactants, detergents, pharmaceuticals, pesticides and vulcanized rubbers [1-7]. Elemental sulfur is usually the by-product of hydrometallurgical leaching of nonferrous sulfide ores. For example, oxygen pressure acid leaching of zinc concentrate (sphalerite) can yield large amounts of elemental sulfur [8-14], and the overall reaction is shown in Equation (1).

$$
\mathrm{ZnS}+\mathrm{H}_{2} \mathrm{SO}_{4}+0.5 \mathrm{O}_{2}=\mathrm{ZnSO}_{4}+\mathrm{H}_{2} \mathrm{O}+\mathrm{S}
$$

As indicated, zinc in sphalerite is transformed into zinc sulfate which can be used to produce zinc metal through electrowinning and sulfur remains in the residue in the form of elemental sulfur [15-18]. The residue is considered to be acid-producing since its sulfur component can react with oxygen and water to generate thiosalts and sulfuric acid [19]. At present, the produced high-sulfur residue is usually subjected to safe storage for most 
zinc refineries in China, which not only causes serious resource waste but also poses huge threat to the environment and human health $[20,21]$. Therefore, it is necessary to recover elemental sulfur from the residue with effective technology.

Elemental sulfur has good natural hydrophobicity, and therefore without the use of any additional agent, it can be efficiently enriched by froth flotation, an extensively used technology in mineral processing for separating target mineral from gangue mineral by using their natural hydrophobicity difference [22-25]. However, the nonferrous metal sulfides $\left(\mathrm{ZnS}, \mathrm{FeS}_{2}, \mathrm{PbS}\right.$ and $\left.\mathrm{Ag}_{2} \mathrm{~S}\right)$ that are not completely oxidized during pressure leaching also remain in the residue [26], and inevitably they will float upward together with elemental sulfur and enter the concentrate because of their similar floatability and intimate association relationship $[27,28]$. This leads to the decrease of elemental sulfur grade in the concentrate product. To enhance the grade, a hot filtration procedure is usually implemented for the concentrate, which can realize the efficient separation of elemental sulfur from the concentrate by melting and filtration at $115-155{ }^{\circ} \mathrm{C}$ [19]. Nevertheless, a significant portion of the elemental sulfur is still hard to separate from the concentrate with hot filtration since this process generally needs raw material whose elemental sulfur content is more than $70 \%$ to ensure a satisfactory performance [26]. The elemental sulfur content in most of the high-sulfur residue is usually in 40-60\% [15], and thus it is difficult to obtain a high elemental sulfur recovery. A feasible method to solve the above problem is to add suitable collector during the flotation procedure to realize the selective flotation of elemental sulfur.

The study aims to find an efficient collector to selectively separate elemental sulfur from a high-sulfur pressure acid leaching residue of zinc sulfide concentrate. First, the flotation performance of O-Isopropyl-N-Ethyl thionocarbamate (IPETC), ammonium dibutyl dithiophosphate (ADDTP) and sodium ethyl xanthate (SEX) for elemental sulfur were compared through a raw ore flotation experiment. Then, pure mineral flotation and adsorption tests were performed to further compare their flotation properties. After that, the structure-activity relationships of three collectors were researched using density functional theory (DFT) calculation through comparing their geometric configurations, electronic structures and corresponding flotation performances. Based on the above results, IPETC was selected as the optimum elemental sulfur collector, and its adsorption mechanism on the elemental sulfur surface was investigated using adsorption simulation calculation and Fourier-transform infrared spectroscopy (FTIR) analysis.

\section{Experimental}

\subsection{Material and Reagents}

The pressure acid leaching residue of zinc sulfide concentrate used in this study was provided by Hulun Buir Chihong Mining Industry Co., Inner Mongolia, China, and it has been used in our previous work [15]. The chemical composition analysis showed that the sulfur content arrived at $46.21 \%$, and $81.97 \%$ of the sulfur occurred in the form of elemental sulfur. Therefore, it was a high-sulfur residue and used for closed-circuit flotation experiment to recover elemental sulfur.

Previous literature showed that natural minerals and minerals after leaching have similar surface properties [29,30], and thus natural minerals are usually adopted as the raw materials for mineral flotation study. According to the result of the X-ray diffraction (XRD) spectra analysis [15], elemental sulfur, sphalerite, pyrite, chalcopyrite, albite and anglesite were the main minerals in the residue, and therefore these pure mineral samples obtained from Guangdong Province in China were chosen for the pure mineral flotation experiment. The high-purity minerals were first collected by handpicking, and then crushed and ground in a porcelain ball mill. Afterwards, the samples were dry-sieved to obtain the $-74+38 \mu \mathrm{m}$ fractions for the flotation experiment, and the fractions of less than $5 \mu \mathrm{m}$ were used for FTIR spectrum measurement. The X-ray fluorescence (XRF) analysis results for the samples in Tables 1-3 showed that their purities were over $96 \%$, which could meet the desirable requirement in this study. 
Table 1. Chemical compositions of pure minerals of elemental sulfur, sphalerite, pyrite and chalcopyrite $($ wt \%).

\begin{tabular}{ccccccc}
\hline Mineral & $\mathbf{C u}$ & $\mathbf{P b}$ & $\mathbf{Z n}$ & $\mathbf{F e}$ & $\mathbf{S}$ & Purity \\
\hline Elemental sulfur & - & - & - & 0.02 & 98.68 & 98.68 \\
Sphalerite & - & 0.04 & 66.20 & 0.52 & 32.9 & 98.65 \\
Pyrite & - & 0.21 & 0.07 & 45.25 & 53.26 & 97.21 \\
Chalcopyrite & 34.13 & 0.01 & 0.27 & 30.10 & 34.22 & 98.76 \\
\hline
\end{tabular}

Note: "—" indicates that the element was not detected.

Table 2. Chemical composition of pure albite mineral (wt \%).

\begin{tabular}{ccccc}
\hline Mineral & $\mathrm{Na}_{\mathbf{2}} \mathbf{O}$ & $\mathbf{A l}_{2} \mathbf{O}_{3}$ & $\mathbf{S i O}_{2}$ & Purity \\
\hline Albite & 11.36 & 19.19 & 67.86 & 96.27 \\
\hline
\end{tabular}

Table 3. Chemical composition of pure anglesite mineral (wt \%).

\begin{tabular}{ccccc}
\hline Mineral & $\mathrm{PbO}$ & $\mathrm{SO}_{3}$ & $\mathrm{Fe}_{2} \mathrm{O}_{3}$ & Purity \\
\hline Anglesite & 69.32 & 28.23 & 0.052 & 96.27 \\
\hline
\end{tabular}

In order to investigate the difference of flotation property of pure minerals and pure minerals after oxygen pressure acid leaching, a comparative experiment was conducted, and the result is shown in Table 4. The method of the flotation test was the same as that in Section Pure Mineral Flotation, and the collector (IPETC) dosage and pulp pH value are $3 \times 10^{-5} \mathrm{~mol} / \mathrm{L}$ and 8.0, respectively. The recoveries of pure minerals of elemental sulfur, sphalerite, pyrite, chalcopyrite, albite and anglesite were $99.2 \%, 51.6 \%, 78.3 \%, 82.5 \%, 23.6 \%$ and $13.3 \%$, respectively, while the recoveries of the above pure minerals after leaching were $99.0 \%, 51.3 \%, 78.2 \%, 82.1 \%, 23.4 \%$ and $13.5 \%$, respectively. Thus, a very close flotation recovery was obtained for each pure mineral and pure mineral after leaching, which can be ascribed to their close floatability. Therefore, it can be deduced that the physical and chemical properties of the surfaces of the pure minerals and pure minerals after leaching are very close.

Table 4. The flotation results of pure minerals and pure minerals after oxygen pressure acid leaching whose conditions are the following: initial sulfuric acid concentration, $60 \mathrm{~g} / \mathrm{L}$, temperature, $150{ }^{\circ} \mathrm{C}$, oxygen partial pressure, $1.0 \mathrm{MPa}$ and time, $2.5 \mathrm{~h}$.

\begin{tabular}{ccccccc}
\hline \multirow{2}{*}{ Raw Material } & \multicolumn{5}{c}{ Recovery (\%) } \\
\cline { 2 - 6 } & Elemental Sulfur & Sphalerite & Pyrite & Chalcopyrite & Anglesite & Albite \\
\hline Pure minerals & 99.2 & 51.6 & 78.3 & 82.5 & 23.6 & 13.3 \\
Pure minerals after oxygen pressure acid leaching & 99.0 & 51.3 & 78.2 & 82.1 & 23.4 & 13.5 \\
\hline
\end{tabular}

The analytically pure O-Isopropyl-N-Ethyl thionocarbamate (IPETC), ammonium dibutyl dithiophosphate (ADDTP) and sodium ethyl xanthate (SEX) were bought from a commercial company of Hunan Province, China, and used as the collector. Methyl isobutyl carbinol (MIBC) from the same company was used as the foaming agent. The other reagents used are also analytically pure. Ultrapure water was used throughout all experiments.

\subsection{Experimental Methods}

\subsubsection{Flotation Experiment}

Raw Ore Flotation

The flotation experiment of pressure acid leaching residue was carried out in a selfaeration XFD-63 flotation machine from Jilin Prospecting Machinery Factory, China [31]. The residue and ultrapure water were first put into the cell to form the pulp with $25 \%$ 
density, and then slime was added to adjust the pulp pH to about 8.0. Afterwards, the inhibitor $\left(\mathrm{Na}_{2} \mathrm{~S}+\mathrm{Na}_{2} \mathrm{SO}_{3}+\mathrm{ZnSO}_{4}\right)$, collector and foaming agent (MIBC) were successively added into the pulp which was agitated at $1650 \mathrm{rpm}$ for $3 \mathrm{~min}$ after adding each reagent. The flotation was conducted for $5 \mathrm{~min}$, and elemental sulfur concentrate and tailing were collected, filtrated, dried, weighed and assayed to calculate elemental sulfur recovery.

\section{Pure Mineral Flotation}

The pure mineral flotation experiment was performed in an XFG5-35 flotation machine (Jilin Prospecting Machinery Factory, Jilin, china) with a $40 \mathrm{~mL}$ plexiglass cell [32]. The agitating speed was kept at $1650 \mathrm{r} \mathrm{min}^{-1}$ with a mechanical impeller. In each test, $2.0 \mathrm{~g}$ pure mineral sample was placed into an ultrasonic bath for $5 \mathrm{~min}$ of cleaning, and then transferred into the flotation cell. After that, the pulp $\mathrm{pH}$ was adjusted to a desired value with dilute $\mathrm{NaOH}$ or $\mathrm{H}_{2} \mathrm{SO}_{4}$ solution. Finally, the collector and the foaming agent were sequentially added into the pulp which was agitated for $2 \mathrm{~min}$. The flotation was carried out for $5 \mathrm{~min}$, and the obtained concentrate and tailing were weighted and analyzed after filtration and drying to calculate mineral recovery.

\subsubsection{FTIR Spectrum}

IPETC solution $\left(1 \times 10^{-2} \mathrm{~mol} / \mathrm{L}\right)$ was first mixed with elemental sulfur sample $(0.5 \mathrm{~g}$, $-38 \mu \mathrm{m})$. After magnetically stirring for $60 \mathrm{~min}$, the solution was filtered, and the obtained solid product was dried at $35^{\circ} \mathrm{C}$ under vacuum for $24 \mathrm{~h}$ for subsequent infrared detection. The Fourier-transform infrared (FTIR) spectra were recorded by a G510PFTIR infrared spectrometer (Nicolet Company, Madison, USA) in the wavenumber range from $400 \mathrm{~cm}^{-1}$ to $4000 \mathrm{~cm}^{-1}$ using the $\mathrm{KBr}$ technique.

\subsubsection{DFT Calculation}

The initial molecular/ion model of collector was constructed and then optimized by MM2 and PM3 methods in Chemoffice 2008 program. The obtained geometry was further optimized by DFT method at the B3LYP/6-31G $(\mathrm{d}, \mathrm{p})$ level in the Gaussian 03 program [31]. Finally, periodic structure optimization was completed in the CASTEP module of Materials Studio 4.4 and then the optimized structure was subjected to DFT calculations.

The calculations of mineral plane and crystal were completed by CASTEP and Dmol3 modules in Materials Studio 4.4 program, in which CASTEP module was used for the establishment of plane and crystal models as well as geometric structure optimization, state density analysis and Mulliken population analysis, and Dmol3 module was used to analyze frontier orbital energy. The plane wave basis set and DND basis set were separately implemented in the CASTEP and Dmol3 modules for the DFT calculations. The establishment and optimization of adsorption model of IPETC on elemental sulfur surface and related calculation were both performed in the CASTEP module of Materials Studio 4.4.

\subsection{Analytical Methods}

The elemental sulfur content in the high-sulfur residue and flotation concentrate was detected by carbon tetrachloride dissolution followed by gravimetric analysis [33]. The concentrations of sulfhydryl collectors were determined by UV-Vis spectroscopy [34].

\section{Results and Discussion}

\subsection{Flotation Performance of Collectors}

Before the use of three collectors IPETC, ADDTP and SEX, single foaming agent MIBC and non-polar collector kerosene were separately used for recovering elemental sulfur from the high-sulfur residue. The flotation sheets are displayed in Figure 1a,b, and the flotation results are shown in Table 5. It can be seen that a low and close elemental sulfur recovery was obtained for MIBC and kerosene. Furthermore, the elemental sulfur grades in the concentrate were low, which is because large amounts of sulfide minerals such as sphalerite, pyrite, chalcopyrite in the residue entered the concentrate with elemental sulfur. 
The above results indicated that the selective and effective separation of elemental sulfur from the high-sulfur residue cannot be realized using MIBC and kerosene.
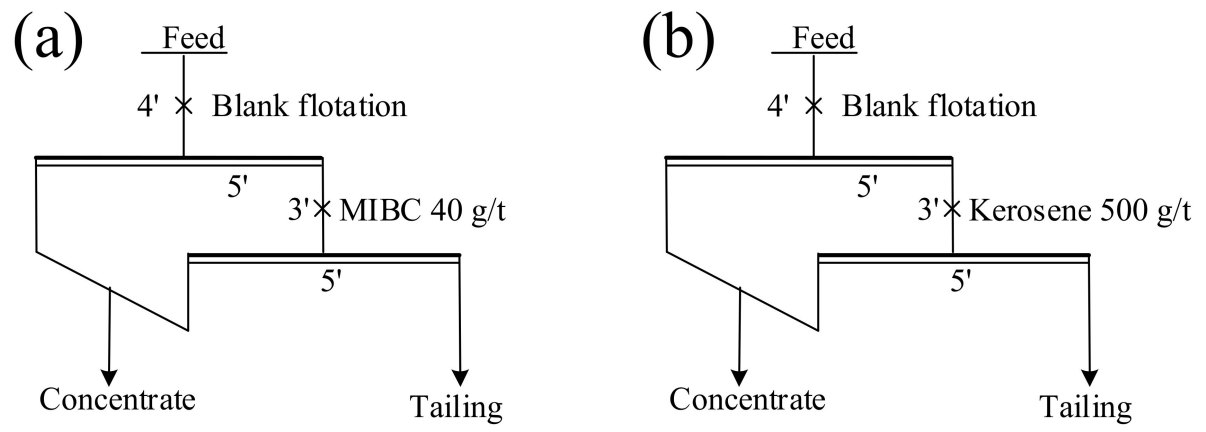

Figure 1. The flotation sheets of high-sulfur residue with MIBC (a) and kerosene (b).

Table 5. The flotation results of high-sulfur residue with MIBC and kerosene.

\begin{tabular}{ccccc}
\hline Collector & Product & Yield (\%) & Elemental Sulfur Grade (\%) & Elemental Sulfur Recovery (\%) \\
\hline \multirow{2}{*}{ MIBC } & Elemental sulfur concentrate & 57.31 & 71.17 & 88.83 \\
& Tailing & 42.69 & 12.02 & 11.17 \\
\hline \multirow{2}{*}{ Kerosene } & Feed residue & 100.00 & 45.92 & 100.00 \\
& Elemental sulfur concentrate & 56.70 & 71.24 & 88.00 \\
& Tailing & 43.30 & 12.72 & 12.00 \\
& Feed residue & 100.00 & 45.90 & 100.00 \\
\hline
\end{tabular}

The flotation performances of IPETC, ADDTP and SEX collectors for elemental sulfur in the high-sulfur residue were compared. After detailed conditional experiment in our laboratory, the closed-circuit flotation flowchart in Figure 2 was ascertained and adopted, and the obtained results are listed in Table 6. Despite the high pulp pH, the collectors will also adsorb a small amount of sphalerite. Thus, zinc sulfate is added to increase the inhibitory effect on sphalerite, even though some zinc ions are present in the pulp itself. It is not necessary to inhibit the gangue minerals in the residue, such as albite and anglesite, because they have poor natural floatability and the sulfhydryl collector (i.e., IPETC) hardly adsorbs on their surfaces.

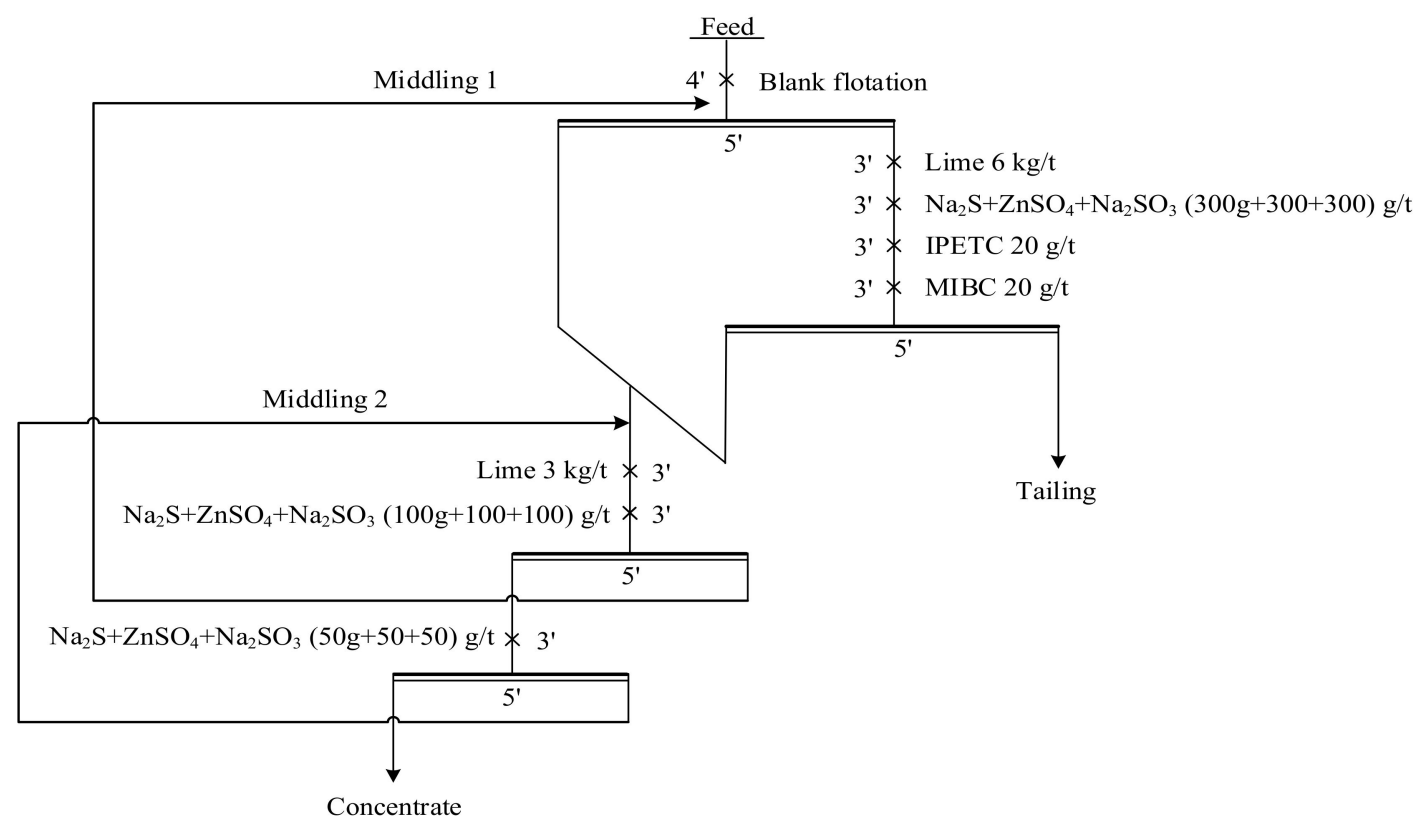

Figure 2. Flowchart of closed-circuit flotation of high-sulfur residue with IPETC, ADDTP and SEX collectors. 
Table 6. The result of closed-circuit flotation of the high-sulfur residue with IPETC, ADDTP and SEX collectors.

\begin{tabular}{|c|c|c|c|c|c|c|}
\hline \multirow{2}{*}{ Collector } & \multirow{2}{*}{ Product } & \multirow{2}{*}{ Yield (\%) } & \multicolumn{2}{|c|}{ Grade (\%) } & \multicolumn{2}{|c|}{ Recovery (\%) } \\
\hline & & & Elemental Sulfur & Zinc & Elemental Sulfur & Zinc \\
\hline \multirow{3}{*}{ SEX } & Elemental sulfur concentrate & 43.55 & 81.53 & 1.33 & 93.67 & 13.33 \\
\hline & Tailing & 56.45 & 4.25 & 6.67 & 6.33 & 86.67 \\
\hline & Feed residue & 100 & 37.91 & 4.34 & 100 & 100 \\
\hline \multirow{3}{*}{ ADDTP } & Elemental sulfur concentrate & 45.47 & 82.25 & 1.15 & 97.83 & 12.08 \\
\hline & Tailing & 54.53 & 1.52 & 6.98 & 2.17 & 87.92 \\
\hline & Feed residue & 100 & 38.23 & 4.33 & 100 & 100 \\
\hline \multirow{3}{*}{ IPETC } & Elemental sulfur concentrate & 44.78 & 84.47 & 0.88 & 99.87 & 9.06 \\
\hline & Tailing & 55.22 & 0.09 & 7.16 & 0.13 & 90.94 \\
\hline & Feed residue & 100 & 37.88 & 4.35 & 100 & 100 \\
\hline
\end{tabular}

From Table 6, the elemental sulfur recoveries for SEX, ADDTP and IPETC were 93.67\%, $97.83 \%$ and $99.87 \%$ while their elemental sulfur grades in the concentrate were $81.53 \%$, $82.25 \%$ and $84.47 \%$, respectively. Thus, both the maximum elemental sulfur recovery and grade were achieved using IPETC collector. The zinc flotation result was also shown in Table 6 . The zinc grades in the elemental sulfur concentrate were $1.33 \%, 1.15 \%$ and $0.88 \%$ for SEX, ADDTP and IPETC, and their recoveries were $13.33 \%, 12.08 \%$ and $9.06 \%$, respectively. Thus, compared with elemental sulfur, only a small amount of zinc was floated and entered the concentrate. Moreover, the zinc grade in the concentrate and its recovery were the lowest for IPETC. The above results indicated that in comparison with SEX and ADDTP, IPETC exhibited more excellent collecting ability and selectivity for elemental sulfur in the high-sulfur residue, and thus it has good industrial application potential.

\subsection{Pure Mineral Flotation and Adsorption Experiments}

\subsubsection{Pure Mineral Flotation Experiment}

The collecting performances of IPETC, ADDTP and SEX for pure minerals of elemental sulfur, sphalerite, pyrite, chalcopyrite, albite and anglesite were compared, and the results of effects of collector dosage and pulp $\mathrm{pH}$ on pure mineral recovery are displayed in Figures $3 a-c$ and $4 a-c$.

As shown in Figure $3 a-c$, the recoveries of elemental sulfur, sphalerite, pyrite and chalcopyrite went up with the increase of IPETC, ADDTP and SEX dosages in their initial ranges of $(2-3) \times 10^{-5},(0.4-1.2) \times 10^{-4}$ and $(0.4-1.2) \times 10^{-4} \mathrm{~mol} / \mathrm{L}$. Afterwards, no obvious increases of the recoveries of four pure minerals were observed with the further increase of collector dosage. Therefore, the optimal IPETC, ADDTP and SEX dosages were separately $3 \times 10^{-5}, 1.2 \times 10^{-4}$ and $1.2 \times 10^{-4} \mathrm{~mol} / \mathrm{L}$. The recoveries of albite and anglesite were low in the whole abscissa range, and collector dosage had little effect on them, which could be ascribed to their poor natural floatability.

As indicated in Figure $4 \mathrm{a}-\mathrm{c}$, the recoveries of elemental sulfur and three sulfides were all augmented as the pulp pH increased in the initial range of 2-8. Nevertheless, further increase of pulp pH from 8 to 12 resulted in the decrease of the recoveries, but the decrease degrees of recoveries of three sulfides were larger than that of elemental sulfur, suggesting that increased $\mathrm{pH}$ had less negative impact on elemental sulfur flotation in this $\mathrm{pH}$ range. Thus, the optimal pulp $\mathrm{pH}$ for the four minerals was 8. The pulp $\mathrm{pH}$ exerted similar effect on anglesite recovery, but its optimum $\mathrm{pH}$ was 6 where the maximum recovery was achieved. The albite recovery gradually dropped in the pulp $\mathrm{pH}$ range of 2-8 and then basically remained steady.

In addition, for each collector, both the maximum elemental sulfur recovery and the differences between the maximum recoveries of elemental sulfur and the other five pure minerals followed the order of IPETC $>$ ADDTP $>$ SDD. Therefore, among the three collectors, IPETC presented the optimal collecting ability and selectivity to elemental sulfur. 

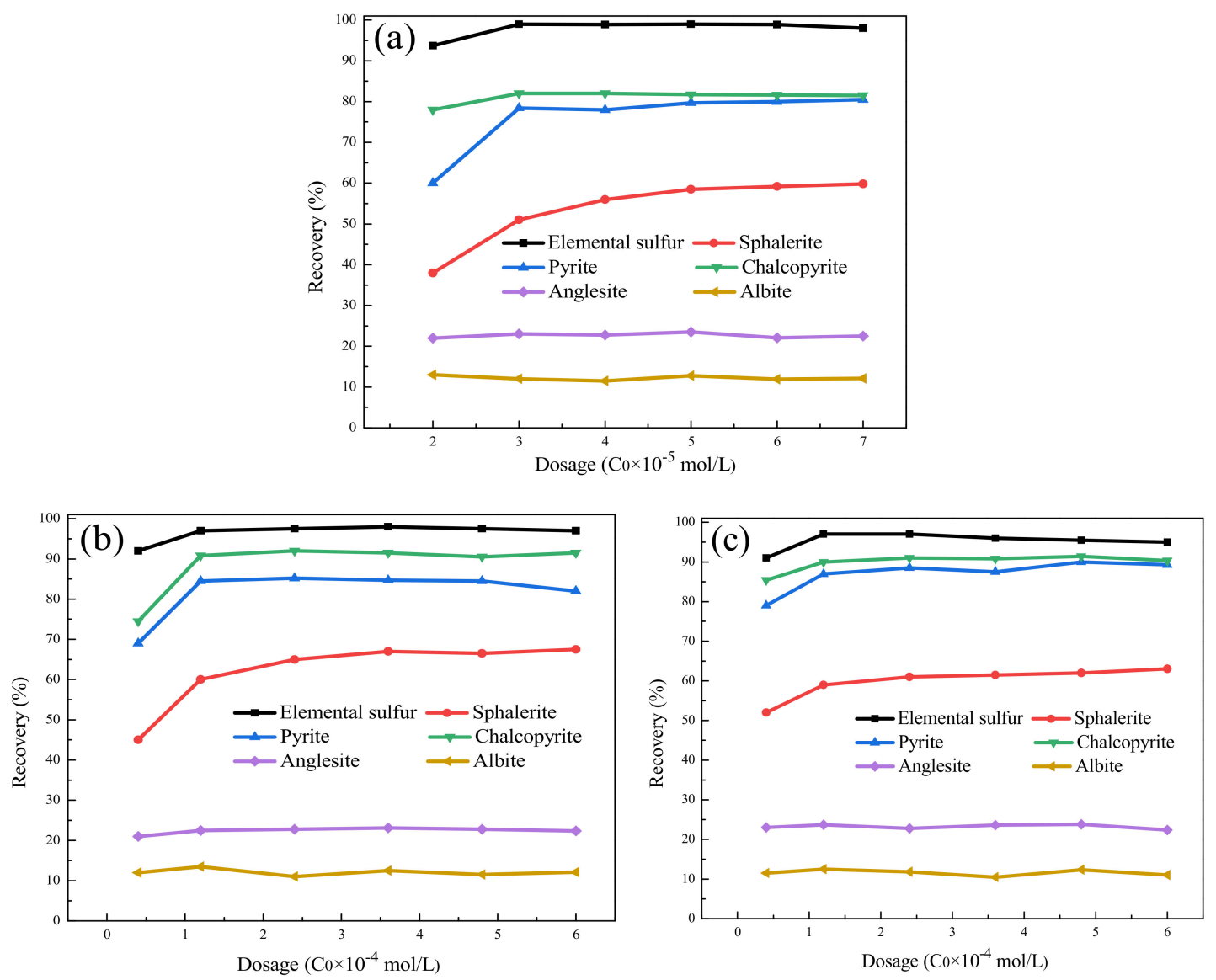

Figure 3. Effect of collector dosage on pure mineral recovery at pulp pH value 8 ((a) IPETC; (b) ADDTP; (c) SEX).
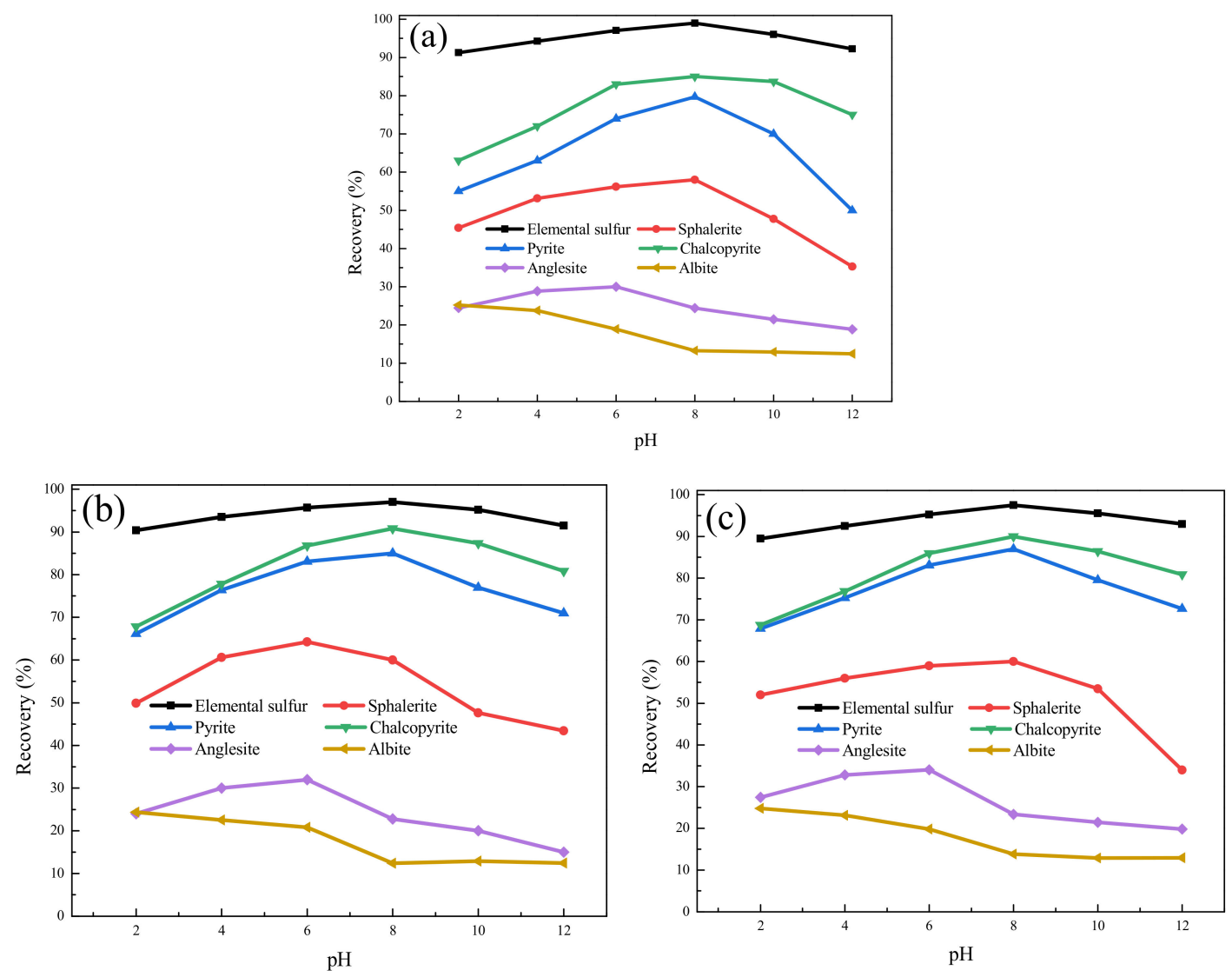

Figure 4. Effect of pulp pH on pure mineral recovery at optimum collector dosage ((a) IPETC; (b) ADDTP; (c) SEX). 


\subsubsection{Pure Mineral Adsorption Experiment}

The adsorption amounts of IPETC, ADDTP and SEX on pure mineral surfaces were also compared, and the effect of initial collector concentration is shown in Figure 5a-c. With the increase of concentrations of three collectors, their adsorption amounts on the surfaces of elemental sulfur, albite and anglesite basically remained steady, but the adsorption amount on elemental sulfur surface kept at a high level while those on the surfaces of albite and anglesite were very low. For sphalerite, pyrite and chalcopyrite, the adsorption amounts of three collectors on their surfaces first increased and then were roughly unchanged.
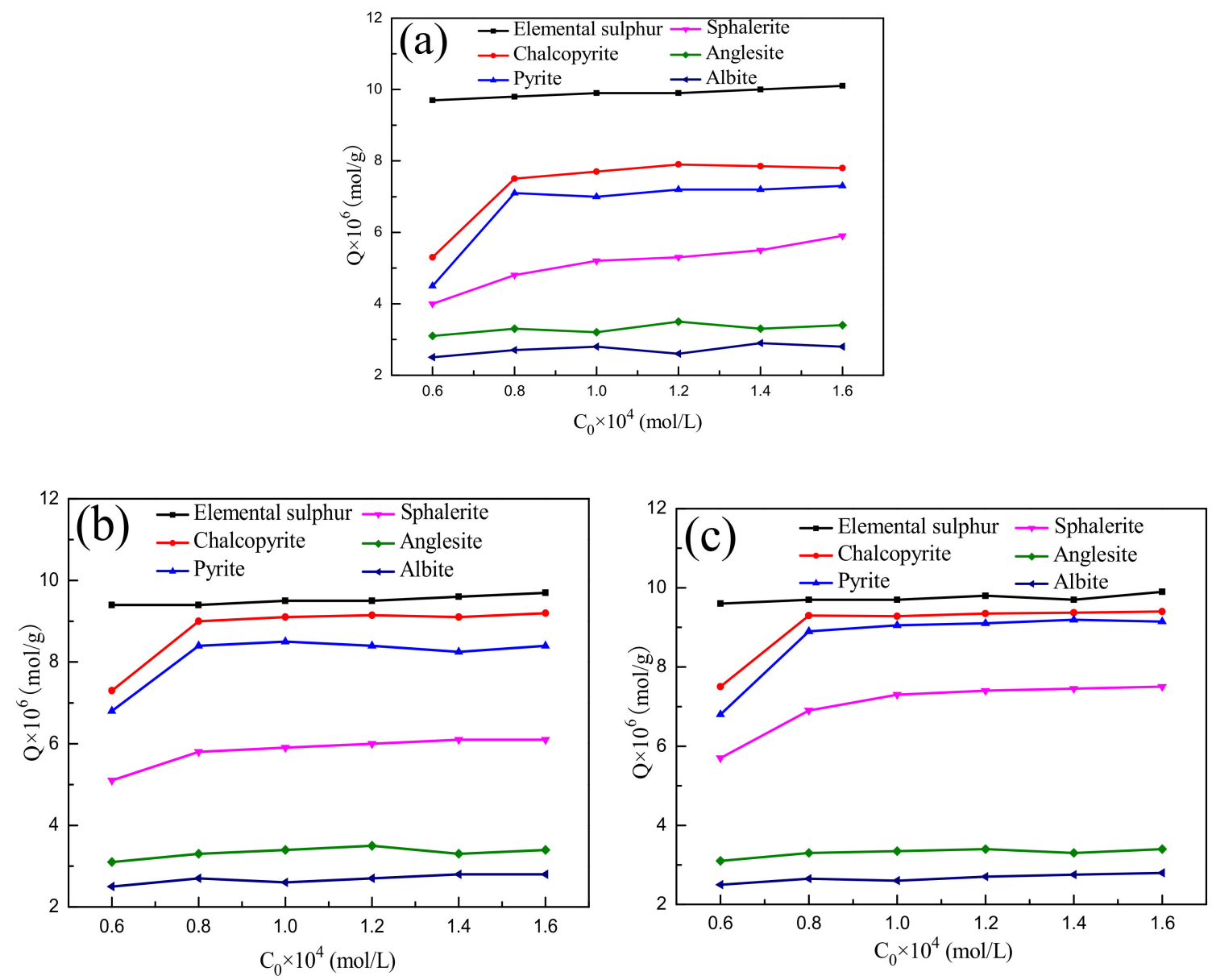

Figure 5. Effect of initial collector concentration on their adsorption amounts on pure mineral surfaces at pulp pH 8 ((a) IPETC; (b) ADDTP; (c) SEX).

However, among the three collectors, the adsorption amount of IPETC on elemental sulfur surface was the biggest under the same collector concentration, suggesting that IPETC possessed the strongest interaction with elemental sulfur surface. Moreover, IPETC exhibited the greatest difference between adsorption quantities on elemental sulfur surface and the surfaces of other pure minerals. The above results indicated that IPETC not only possessed the biggest adsorption amount on elemental sulfur surface but also displayed the best adsorption selectivity for elemental sulfur, which is consistent with the result of the pure mineral flotation test in Section 3.2.1.

\subsection{Structure-Property Relationships of Collectors \\ 3.3.1. Geometry Configuration}

The simulation calculations of collector molecules/ion were carried to study their structure-property relationships. The optimized geometry configurations of ADDTP, SEX 
and IPETC are presented in Figure $6 \mathrm{a}-\mathrm{c}$, and the bond lengths and dihedral angles are displayed in Table 7.

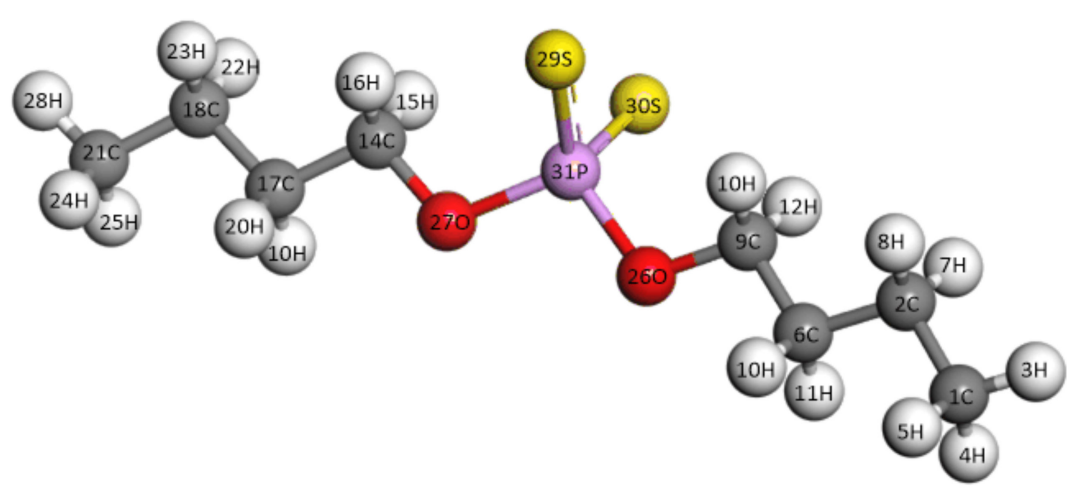

(a)

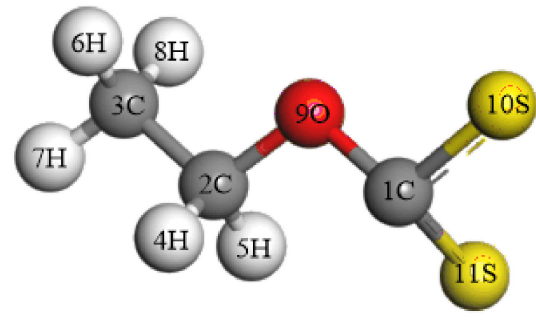

(b)

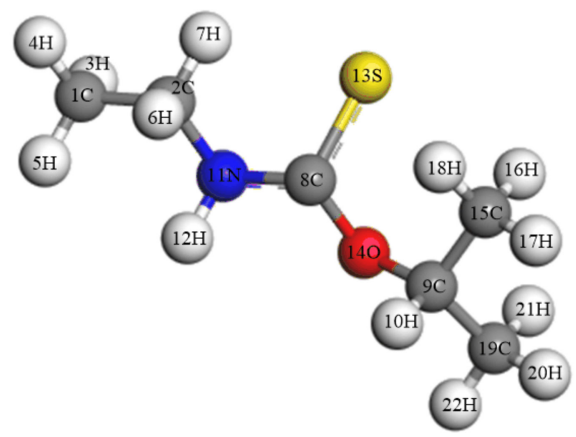

(c)

Figure 6. Optimized geometry configurations of collector molecules or ions ((a) IPETC; (b) ADDTP; (c) SEX).

Table 7. Bond lengths and dihedral angles of collectors.

\begin{tabular}{ccccc}
\hline Collector & \multicolumn{2}{c}{ Bond Length $(\AA)$} & \multicolumn{2}{c}{ Dihedral Angle $\left(^{\circ}\right.$ ) } \\
\hline \multirow{2}{*}{ SEX } & $1 \mathrm{C}-10 \mathrm{~S}$ & $1 \mathrm{C}-11 \mathrm{~S}$ & \multicolumn{2}{c}{$9 \mathrm{O}-1 \mathrm{C}-10 \mathrm{~S}-11 \mathrm{~S}$} \\
& 1.707 & 1.699 & 179.992 \\
\hline \multirow{2}{*}{ ADDTP } & $29 \mathrm{~S}-31 \mathrm{P}$ & $30 \mathrm{~S}-31 \mathrm{P}$ & $14 \mathrm{C}-27 \mathrm{O}-31 \mathrm{P}-29 \mathrm{~S}$ & $9 \mathrm{C}-26 \mathrm{O}-31 \mathrm{P}-30 \mathrm{~S}$ \\
& 2.006 & 2.006 & -59.008 & -59.003 \\
\hline \multirow{2}{*}{ IPETC } & \multicolumn{2}{c}{$8 \mathrm{C}-13 \mathrm{~S}$} & $13 \mathrm{~S}-8 \mathrm{C}-11 \mathrm{~N}-2 \mathrm{C}$ & $11 \mathrm{~N}-8 \mathrm{C}-14 \mathrm{O}-9 \mathrm{C}$ \\
& \multicolumn{2}{c}{1.679} & -178.654 & 177.847 \\
\hline
\end{tabular}

The bond length of carbonyl S atom in SEX is longer than that in IPETC, indicating that carbonyl $S$ in IPETC is less likely to lose electrons. As a result of this, normal covalent bond is easier to be generated in SEX, which is not unbeneficial to its selectivity. Therefore, 
IPETC presents a better collecting selectivity for elemental sulfur in terms of bond length of carbonyl $\mathrm{S}$ atom. The carbonyl $\mathrm{S}$ atom in ADDTP bonds with the $\mathrm{P}$ atom to form a $\mathrm{P}=\mathrm{S}$ bond which is different with $\mathrm{C}=\mathrm{S}$ bond in SEX and IPETC, and thus their bond lengths are not comparable.

Judging from the dihedral angle of three collectors, the atoms of $-\mathrm{S}-\mathrm{C}=\mathrm{N}-\mathrm{C}-$ and $-\mathrm{N}$ $\mathrm{C}=\mathrm{O}-\mathrm{C}$ - groups in IPETC and $-\mathrm{O}-\mathrm{C}(=\mathrm{S})-\mathrm{S}$ - group in SEX are nearly located in the same plane, respectively. Furthermore, the $\mathrm{p}$ orbitals that are not involved in hybridization exist in the valence electron layers of these atoms. Thus, conjugated big $\pi$-bond is easy to be formed in the three groups.

\subsubsection{Electronic Structure}

Mulliken Population Analysis

The Mulliken populations of bond and atom charge of SEX, ADDTP and IPETC are indicated in Table 8. The sequence of bond populations of $\mathrm{C}=\mathrm{S}$ or $\mathrm{P}=\mathrm{S}$ bonds in the three collectors is IPETC $>$ ADDTP $>$ SEX. A larger population means stronger covalency of the covalent bond. Thus, in comparison with IPETC, it is more likely for the carbonyl S atoms in ADDTP and SEX to offer electrons, leading to the easier generation of a normal covalent bond between collector and mineral surface. Therefore, in terms of the bond population, IPETC shows better selectivity to elemental sulfur.

Table 8. Mulliken populations of $\mathrm{C}=\mathrm{S}$ or $\mathrm{P}=\mathrm{S}$ bond and atom charge of collectors.

\begin{tabular}{ccccccc}
\hline Collector & \multicolumn{2}{c}{ Bond Population } & \multicolumn{4}{c}{ Atom Charge Population } \\
\hline \multirow{2}{*}{ SEX } & $10 S-1 C$ & $11 S-1 C$ & $1 \mathrm{C}$ & $9 \mathrm{O}$ & $10 \mathrm{~S}$ & $11 \mathrm{~S}$ \\
& 0.41 & 0.31 & -0.099 & -0.174 & -0.379 & -0.405 \\
\hline \multirow{2}{*}{ ADDTP } & $29 \mathrm{~S}-31 \mathrm{P}$ & $30 \mathrm{~S}-31 \mathrm{P}$ & $27 \mathrm{O}$ & $29 \mathrm{~S}$ & $30 \mathrm{~S}$ & $31 \mathrm{P}$ \\
& 0.72 & 0.74 & -0.729 & -0.759 & -0.811 & 1.521 \\
\hline \multirow{2}{*}{ IPETC } & \multicolumn{2}{c}{$8 \mathrm{C}-13 \mathrm{~S}$} & $8 \mathrm{C}$ & $11 \mathrm{~N}$ & $13 \mathrm{~S}$ & $14 \mathrm{O}$ \\
& \multicolumn{2}{c}{1.00} & 0.067 & 0.022 & -0.206 & -0.238 \\
\hline
\end{tabular}

The absolute values of Mulliken charge populations of carbonyl $S$ atoms follow the order of ADDTP > SEX > IPETC. A larger absolute value means stronger electrostatic attraction between carbonyl $\mathrm{S}$ atom in collector and $\mathrm{S}$ atom in elemental sulfur surface. Nevertheless, electrostatic interaction has no directivity, and therefore the larger absolute value is unfavorable to the collector selectivity. Thus, in terms of atom charge population, IPETC also exhibits better selectivity for elemental sulfur than ADDTP and SEX.

\section{Density of States Analysis}

The densities of states of three collectors are indicated in Figure $7 \mathrm{a}-\mathrm{c}$. The valence band tops of SEX, ADDTP and IPETC are mainly comprised of 3p orbitals of 10S and 11S, $29 \mathrm{~S}$ and 30S, and $13 \mathrm{~S}$ atoms, respectively. Their conduction band bottoms are primarily comprised of $2 p$ orbitals of $1 \mathrm{C}$ and $9 \mathrm{O}$ atoms and $3 p$ orbitals of $10 \mathrm{~S}$ and $11 \mathrm{~S}$ atoms, $2 \mathrm{p}$ orbitals of 26O, 27O and 31P atoms and 3p orbitals of $29 \mathrm{~S}$ and $30 \mathrm{~S}$ atoms, and $2 \mathrm{p}$ orbitals of $8 \mathrm{C}, 11 \mathrm{~N}$ and $14 \mathrm{O}$ atoms and $3 \mathrm{p}$ orbital of $13 \mathrm{~S}$ atom, respectively. According to the band theory, the valence band top is the highest occupied molecular orbital (HOMO), and the conduction band bottom is the lowest unoccupied molecular orbital (LUMO), and they have the highest chemical activity and are separately apt to lose and gain electrons. Therefore, it can be concluded that the oxidation reaction centers of SEX, ADDTP and IPETC are separately $10 \mathrm{~S}$ and 11S, $29 \mathrm{~S}$ and 30S, and $13 \mathrm{~S}$ atoms. Accordingly, the reduction reactions can occur on 1C, 9O, 10S and 11S atoms for SEX, 26O, 27O, 29S, 30S and 31P atoms for ADDTP, and $8 \mathrm{C}, 11 \mathrm{~N}, 13 \mathrm{~S}$ and $14 \mathrm{O}$ atoms for IPETC, respectively. 

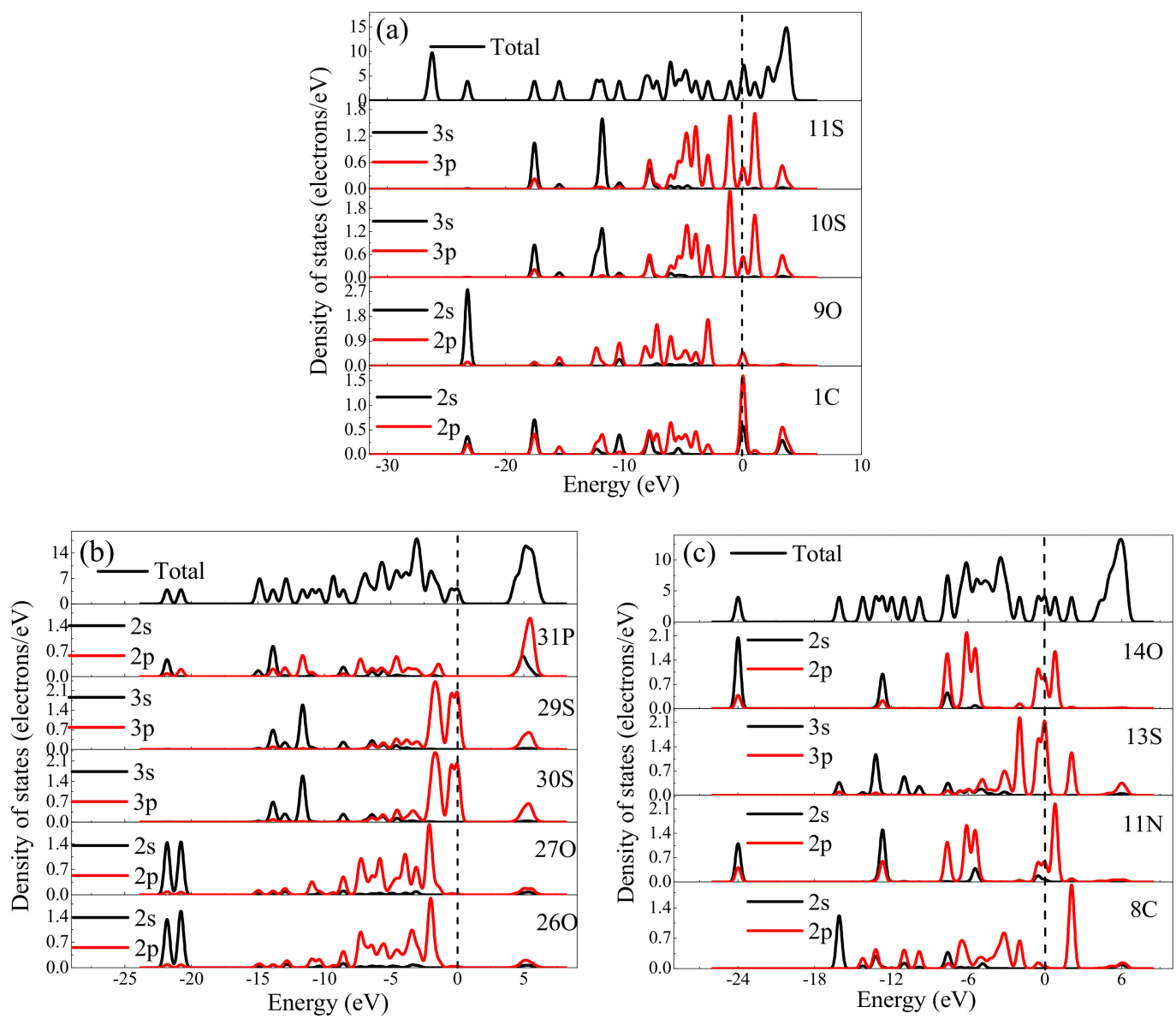

Figure 7. Densities of states of collectors ((a) IPETC; (b) ADDTP; (c) SEX).

Frontier Orbital Analysis

The electronic cloud pictures of frontier molecular orbitals of three optimized SEX, ADDTP and IPETC models are given in Figure 8a-f. From these subgraphs, the HOMOs of SEX, ADDTP and IPETC are mainly composed of electron orbitals of $10 \mathrm{~S}$ and 11S, $29 \mathrm{~S}$ and 30S, and $13 \mathrm{~S}$ atoms, respectively. The LUMOs are primarily constituted by electron orbitals of 1C, 9O, 10S and 11S atoms for SEX, 26O, 27O, 29S, 30S and 31P atoms for ADDTP, and $8 \mathrm{C}, 11 \mathrm{~N}, 13 \mathrm{~S}$ and $14 \mathrm{O}$ atoms for IPETC, respectively. The above results are consistent with the results of density of states analysis in Section Density of States Analysis. Furthermore, the atoms of $-\mathrm{S}-\mathrm{C}=\mathrm{N}-\mathrm{C}-$ and $-\mathrm{N}-\mathrm{C}=\mathrm{O}-\mathrm{C}-$ groups in IPETC and $-\mathrm{O}-\mathrm{C}(=\mathrm{S})-\mathrm{S}$ - group in SEX are all almost in the same plane based on the dihedral angle values in Table 7. Moreover, it can be known from the result of density of states analysis in Section Density of States Analysis that the LUMO orbitals of IPETC and SEX all constitute the $p$ orbital of each atom in these functional groups. Therefore, it can be inferred that the LUMO orbitals of IPETC and SEX both are conjugated big $\pi$-bonds formed by electron orbitals of these functional groups. 


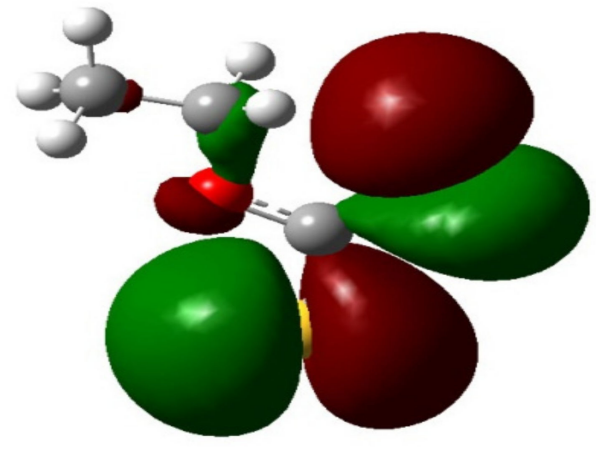

(a)

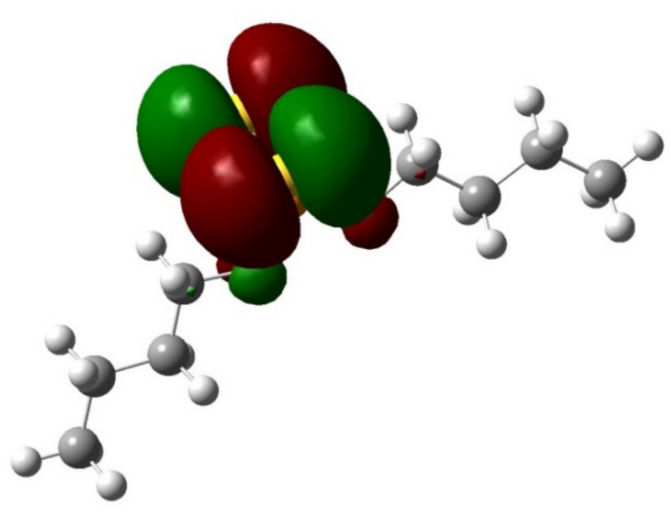

(c)

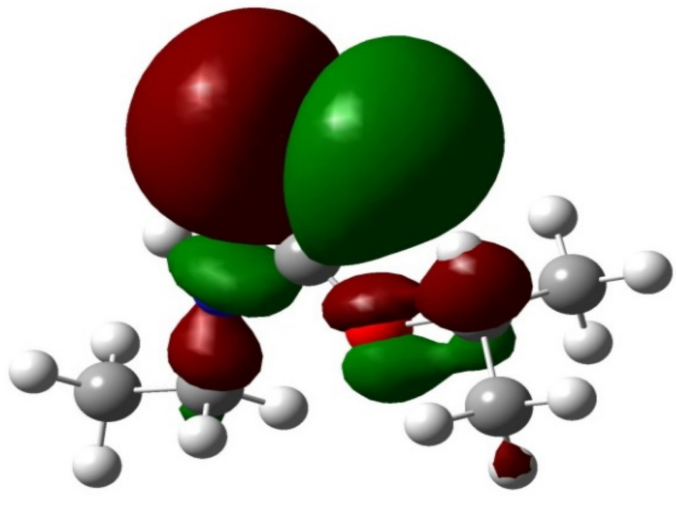

(e)

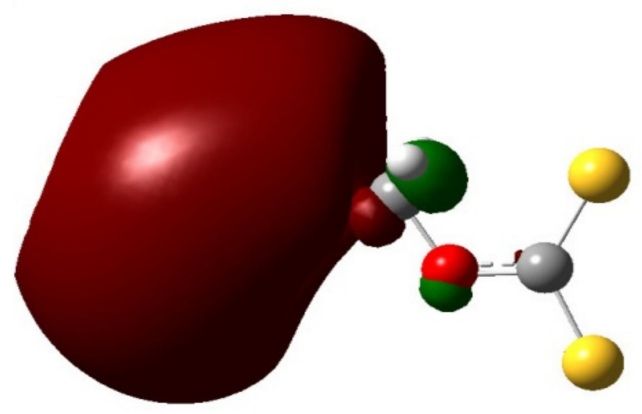

(b)

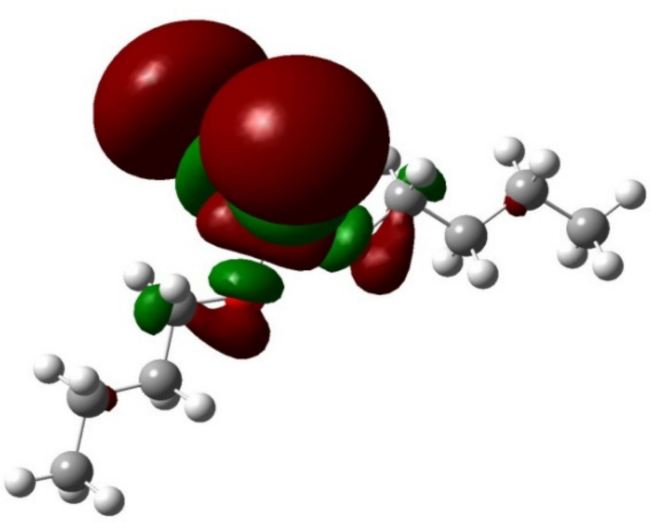

(d)

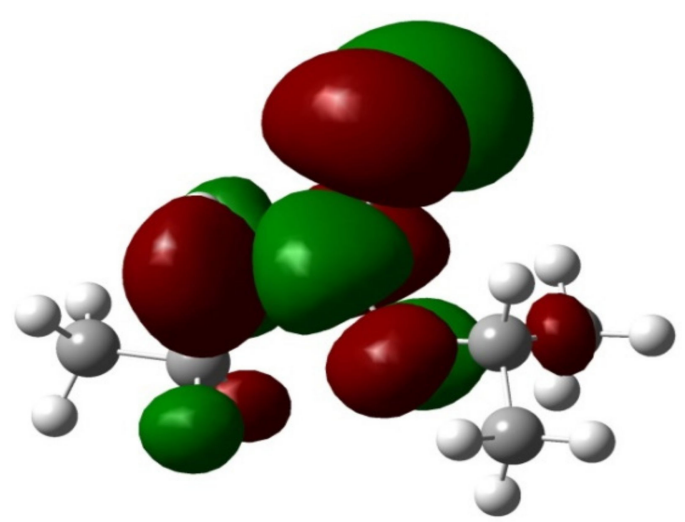

(f)

Figure 8. Electron cloud pictures of frontier molecular orbitals of optimized collector models ((a) HOMO of SEX; (b) LUMO of SEX; (c) HOMO of ADDTP; (d) LUMO of ADDTP; (e) HOMO of IPETC; (f) LUMO of IPETC).

The frontier orbital energies of three collectors and energy differences between collectors and minerals $(\Delta \mathrm{E})$ are shown in Table 9. According to frontier molecular orbital theory, a smaller absolute value of energy difference between the HOMO of one reactant and the LUMO of another one means that they are prone to react with each other. $\Delta \mathrm{E}_{1}$ are all evidently smaller than $\Delta \mathrm{E}_{2}$, suggesting that the chemical reaction between collectors and minerals is led by the electron transfer from collectors to minerals. Thus, the normal covalent bond predominates in the interaction. $\Delta \mathrm{E}_{1}$ between each collector and elemental sulfur is smaller than that between each collector and chalcopyrite/sphalerite/pyrite/anglesite/albite, indicating that the normal covalent bond between 
each collector and elemental sulfur is stronger than that between each collector and five other minerals. In comparison with SEX and ADDTP, both $\triangle \mathrm{E}_{1}$ between IPETC and elemental sulfur and $\Delta \mathrm{E}_{1}$ elemental sulfur $/ \Delta \mathrm{E}_{1}$ five other minerals of IPETC are the minimum. Thus, IPETC displays the optimal collecting power and selectivity for elemental sulfur among the three collectors.

Table 9. Frontier orbital energies of collectors and energy differences between collectors and minerals.

\begin{tabular}{clllcccccc}
\hline Collector & Orbital Energy (eV) & $\Delta \mathrm{E}^{\mathbf{a}}$ & Elemental Sulfur & Chalcopyrite & Pyrite & Sphalerite & Anglesite & Albite \\
\hline \multirow{2}{*}{ SEX } & HOMO & -4.57 & $\Delta \mathrm{E}_{1}$ & 0.39 & 0.64 & 0.78 & 1.54 & 1.69 & 1.77 \\
& LUMO & -3.07 & $\Delta \mathrm{E}_{2}$ & 2.55 & 2.60 & 2.21 & 2.38 & 2.44 & 2.67 \\
\hline \multirow{2}{*}{ ADDTP } & HOMO & -5.56 & $\Delta \mathrm{E}_{1}$ & 0.32 & 0.51 & 0.53 & 0.73 & 0.95 & 1.23 \\
& LUMO & -4.67 & $\Delta \mathrm{E}_{2}$ & 2.42 & 1.00 & 1.37 & 2.04 & 2.31 & 2.45 \\
\hline \multirow{2}{*}{ IPETC } & HOMO & -5.18 & $\Delta \mathrm{E}_{1}$ & 0.15 & 0.76 & 1.04 & 1.43 & 1.51 & 1.76 \\
& LUMO & -3.76 & $\Delta \mathrm{E}_{2}$ & 1.91 & 1.86 & 1.77 & 1.91 & 1.97 & 2.12 \\
\hline
\end{tabular}

${ }^{\mathrm{a}} \Delta \mathrm{E}_{1}=\mid \mathrm{E}(\mathrm{HOMO}$, collector $)-\mathrm{E}(\mathrm{LUMO}$, mineral $) \mid$ and $\Delta \mathrm{E}_{2}=\mid \mathrm{E}(\mathrm{HOMO}$, mineral $)-\mathrm{E}(\mathrm{LUMO}$, collector $) \mid$.

\subsection{Mechanism of IPETC Adsorption on Elemental Sulfur Surface}

\subsubsection{Adsorption Configuration and Adsorption Energy}

After many adsorption position tests, six possible configurations of IPETC adsorption on perfect elemental sulfur (110) plane are indicated in Figure $9 \mathrm{a}-\mathrm{f}$, and the adsorption energies are shown in Table 10. The adsorption energies of six configurations are all negative, and therefore these adsorption reactions can happen spontaneously. Nevertheless, the adsorption energy is the lowest for the configuration of simultaneous adsorption of carbonyl $\mathrm{S}$ together with $\mathrm{O}$, suggesting that this configuration is the most stable.

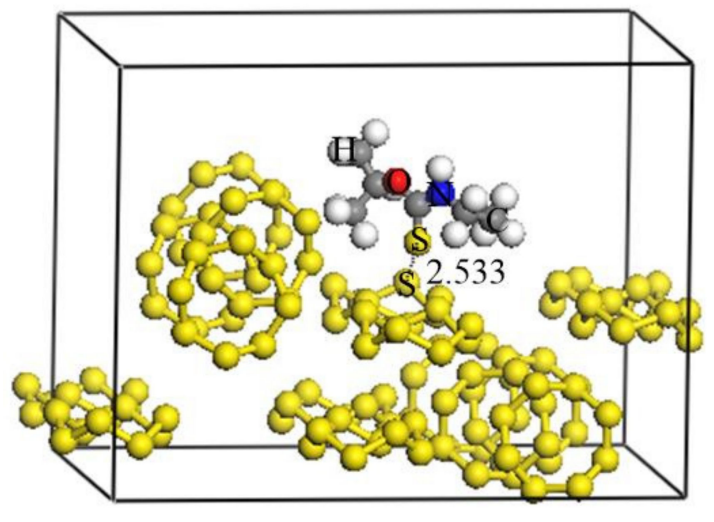

(a)

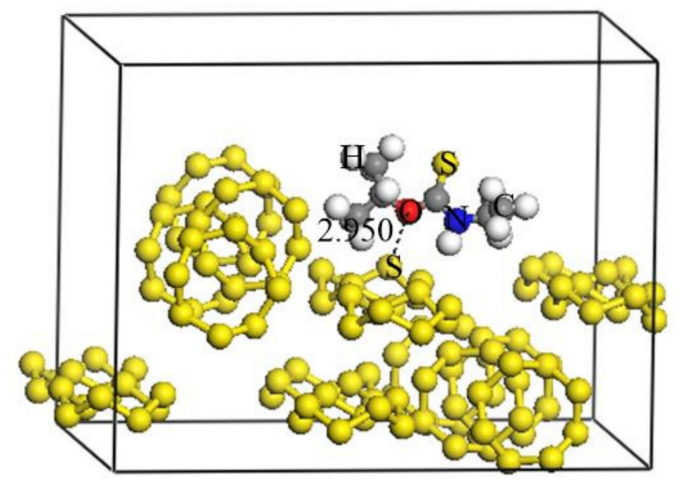

(c)

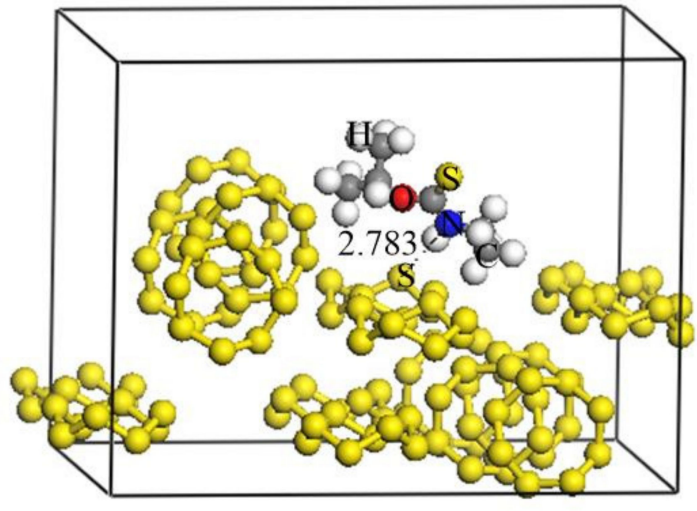

(b)

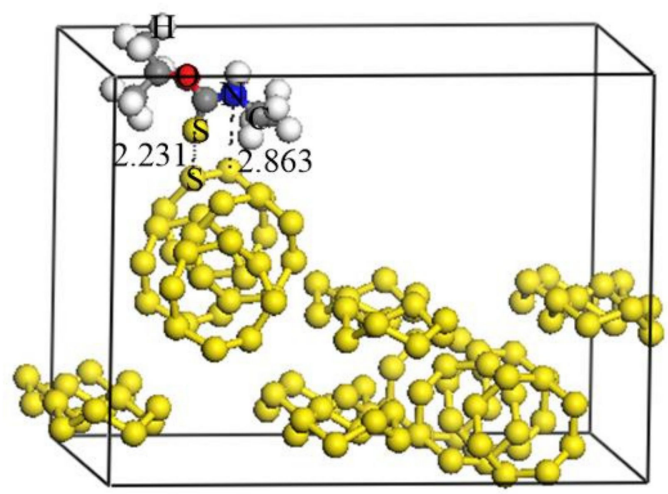

(d)

Figure 9. Cont. 


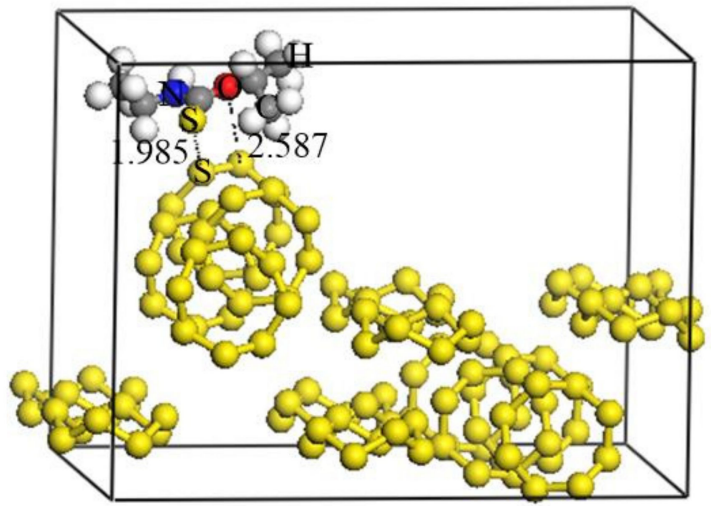

(e)

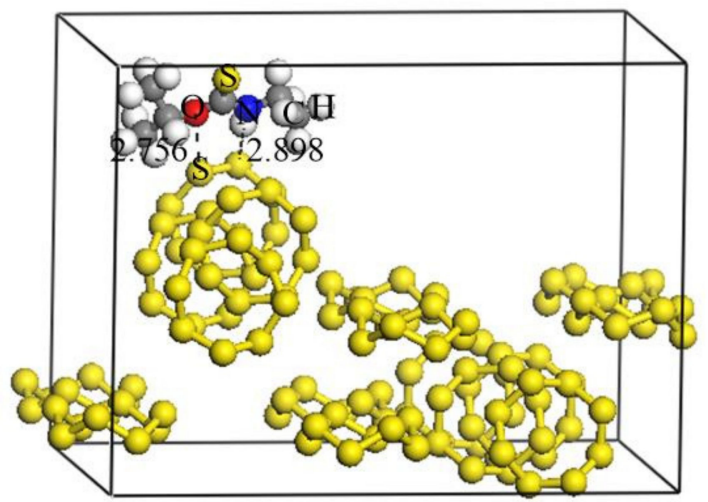

(f)

Figure 9. Adsorption configurations of IPETC on perfect elemental sulfur (100) crystal plane ((a) adsorption of carbonyl S atom; (b) adsorption of $\mathrm{N}$ atom; (c) adsorption of $\mathrm{O}$ atom; (d) adsorption of carbonyl $\mathrm{S}$ together with $\mathrm{N}$ atoms; (e) adsorption of carbonyl $\mathrm{S}$ together with $\mathrm{O}$ atoms; (f) adsorption of $\mathrm{N}$ together with $\mathrm{O}$ atoms).

Table 10. Adsorption energy of each adsorption configuration of IPETC on elemental sulfur (110) crystal plane.

\begin{tabular}{cc}
\hline Adsorption Configuration & Adsorption Energy (kJ/mol) \\
\hline Adsorption of carbonyl S & -19.79 \\
Adsorption of N & -10.23 \\
Adsorption of O & -6.16 \\
Simultaneous adsorption of carbonyl S together with N & -21.82 \\
Simultaneous adsorption of carbonyl S together with O & -26.98 \\
Simultaneous adsorption of N and O & -16.53 \\
\hline
\end{tabular}

The adsorption energies of six configurations of IPETC adsorption on the perfect crystal planes of chalcopyrite (112), sphalerite (110), pyrite (100), anglesite (001) and albite (001) are displayed in Table 11. Obviously, the most stable adsorption configuration of IPETC on the five crystal planes is also the simultaneous adsorption of carbonyl $S$ together with $\mathrm{O}$. Nevertheless, the adsorption energies for the first four minerals are negative and obey the sequence of chalcopyrite $<$ pyrite $<$ sphalerite $<$ anglesite, which are all larger than that for elemental sulfur in Table 9. Thus, it is easier for IPETC adsorption on elemental sulfur surface to occur. The adsorption energies for albite are all positive, and therefore IPETC adsorption on albite surface is difficult, which supported the results of pure mineral flotation and adsorption experiments in Section 3.2 that both the albite recovery and its adsorption amount on albite surface are very low.

Table 11. Adsorption energy of each adsorption configuration of IPETC on each crystal plane.

\begin{tabular}{|c|c|c|c|c|c|}
\hline \multirow[b]{2}{*}{ Adsorption Configuration } & \multicolumn{5}{|c|}{ Adsorption Energy (kJ/mol) } \\
\hline & $\begin{array}{l}\text { Chalcopyrite } \\
\text { (112) Plane }\end{array}$ & $\begin{array}{c}\text { Pyrite } \\
\text { (100) Plane }\end{array}$ & $\begin{array}{l}\text { Sphalerite (110) } \\
\text { Plane }\end{array}$ & $\begin{array}{l}\text { Anglesite } \\
\text { (001) Plane }\end{array}$ & $\begin{array}{c}\text { Albite (001) } \\
\text { Plane }\end{array}$ \\
\hline Adsorption of carbonyl S & -12.53 & -11.12 & -10.02 & -3.53 & 1.54 \\
\hline Adsorption of $\mathrm{N}$ & -6.88 & -3.78 & -2.12 & -1.38 & 4.10 \\
\hline Adsorption of $\mathrm{O}$ & -9.12 & -8.00 & -7.79 & -3.19 & 2.16 \\
\hline Simultaneous adsorption of carbonyl S together with $\mathrm{N}$ & -8.01 & -4.56 & -3.45 & -2.41 & 2.33 \\
\hline Simultaneous adsorption of carbonyl S together with $\mathrm{O}$ & -16.89 & -14.69 & -12.21 & -4.67 & 1.23 \\
\hline Simultaneous adsorption of $\mathrm{N}$ and $\mathrm{O}$ & -5.13 & -6.69 & -5.63 & -0.43 & 3.49 \\
\hline
\end{tabular}

The steadiest adsorption configurations of IPETC on perfect planes of chalcopyrite, pyrite, sphalerite and anglesite are presented in Figure $10 \mathrm{a}-\mathrm{d}$, and the Mulliken populations of corresponding adsorption bonds are shown in Table 12. For each configuration, the 
population of carbonyl $\mathrm{S}$ adsorption bond is much bigger than that of $\mathrm{O}$ adsorption bond.

Thus, the interaction between carbonyl $\mathrm{S}$ and bonding atom in mineral surface is stronger.

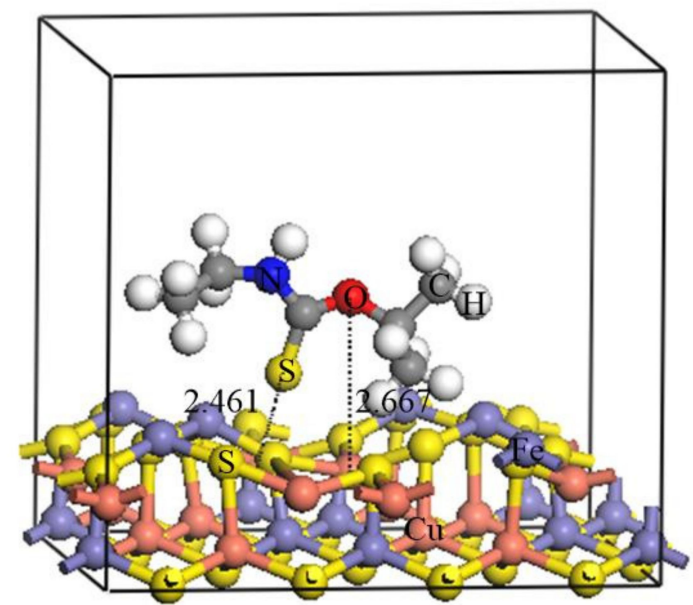

(a)

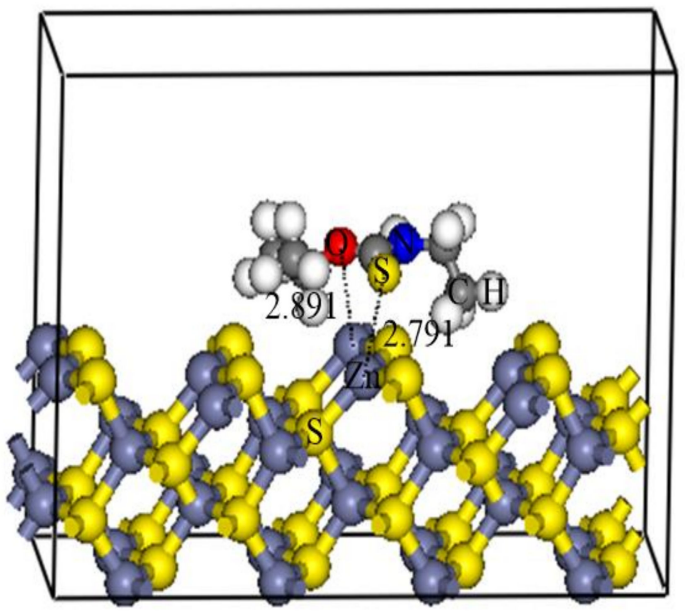

(c)

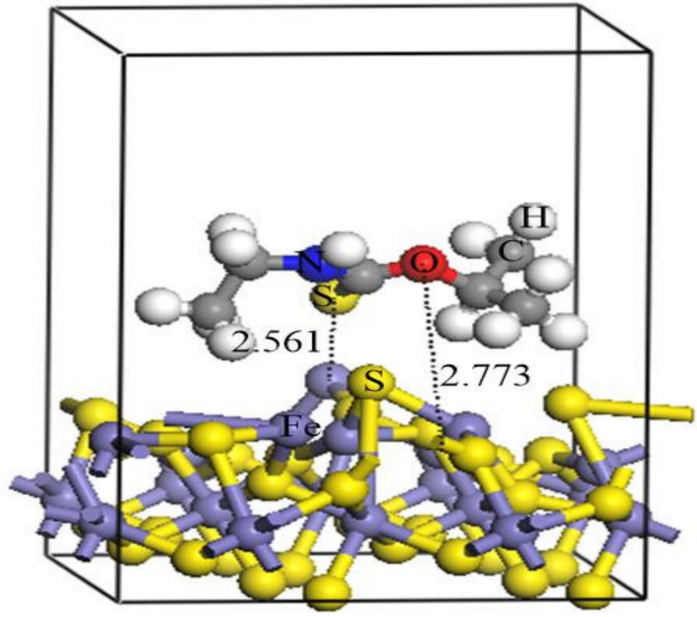

(b)

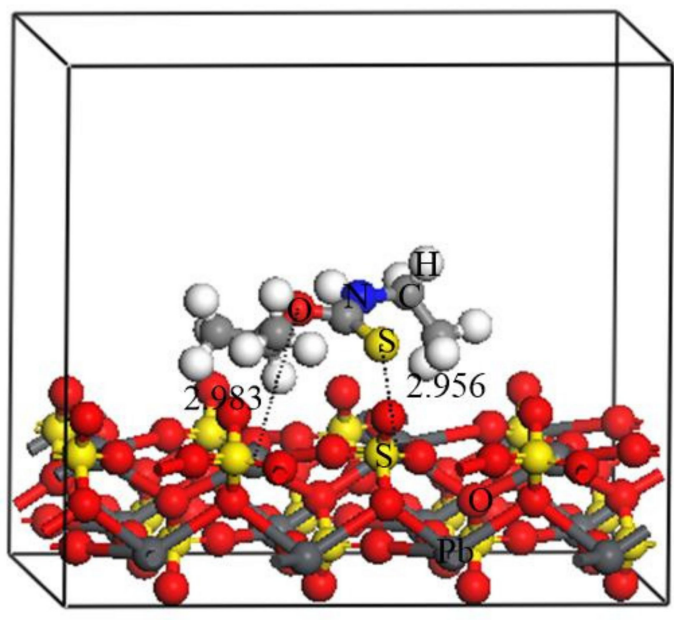

(d)

Figure 10. The steadiest adsorption configurations of IPETC on perfect crystal planes of chalcopyrite (112) (a), pyrite (100) (b), sphalerite (110) (c) and anglesite (001) (d).

Table 12. Mulliken population of adsorption bonds of each steadiest adsorption configuration of IPETC on each crystal plane.

\begin{tabular}{cccc}
\hline Crystal Plane & Adsorption Bond & Bond Length (Å) & Mulliken Population \\
\hline \multirow{2}{*}{ Elemental sulfur (110) } & S-S & 1.985 & 0.42 \\
& O-S & 2.587 & 0.15 \\
\hline \multirow{2}{*}{ Chalcopyrite (112) } & S-Cu & 2.461 & 0.35 \\
& O-Cu & 2.667 & 0.12 \\
\hline \multirow{2}{*}{ Pyrite (100) } & S-Fe & 2.561 & 0.33 \\
& O-Fe & 2.773 & 0.08 \\
\hline \multirow{2}{*}{ Sphalerite (110) } & $\mathrm{S}-\mathrm{Zn}$ & 2.791 & 0.23 \\
& $\mathrm{O}-\mathrm{Zn}$ & 2.891 & 0.11 \\
\hline \multirow{2}{*}{ Anglesite (001) } & $\mathrm{S}-\mathrm{Pb}$ & 2.956 & 0.19 \\
& $\mathrm{O}-\mathrm{Pb}$ & 2.983 & 0.12 \\
\hline
\end{tabular}




\subsubsection{Mulliken Population and Density of States Analyses}

The Mulliken populations and densities of states of bonding atoms before and after IPETC adsorption on perfect elemental sulfur (100) plane are presented in Table 13 and Figure 11, respectively. The $3 p$ orbital of carbonyl S atom of IPETC donates some electrons to the $3 p$ orbital of $S$ atom on elemental sulfur surface to form a normal covalent bond, while the $2 p$ orbital of $\mathrm{O}$ atom of IPETC accepts the electrons from the $3 p$ orbital of $S$ atom in elemental sulfur surface to form a backdonation covalent bond.

Table 13. Mulliken charge populations of bonding atoms before and after adsorption.

\begin{tabular}{cccccc}
\hline \multirow{2}{*}{ Bonding Atom } & \multirow{2}{*}{ Adsorption State } & \multicolumn{3}{c}{ Electron Charge (e) } & \multirow{2}{*}{ Charge Population } \\
\cline { 3 - 5 } & & $\mathbf{s}$ & $\mathbf{p}$ & $\mathbf{d}$ & \\
\hline \multirow{2}{*}{$\mathrm{O}_{(\mathrm{O}-\mathrm{S})}$} & Before adsorption & 1.77 & 4.66 & 0.00 & -0.44 \\
& After adsorption & 1.77 & 4.71 & 0.00 & -0.46 \\
\hline \multirow{2}{*}{$\mathrm{S}_{(\mathrm{O}-\mathrm{S})}$} & Before adsorption & 1.89 & 4.19 & 0.00 & -0.01 \\
& After adsorption & 1.89 & 4.12 & 0.00 & -0.07 \\
\hline \multirow{2}{*}{ Carbonyl S } & Before adsorption & 1.82 & 4.41 & 0.00 & -0.23 \\
& After adsorption & 1.82 & 4.10 & 0.00 & 0.05 \\
\hline \multirow{2}{*}{$\mathrm{S}_{(\mathrm{S}-\mathrm{S})}$} & Before adsorption & 1.89 & 4.10 & 0.00 & 0.01 \\
& After adsorption & 1.89 & 4.12 & 0.00 & -0.01 \\
\hline
\end{tabular}

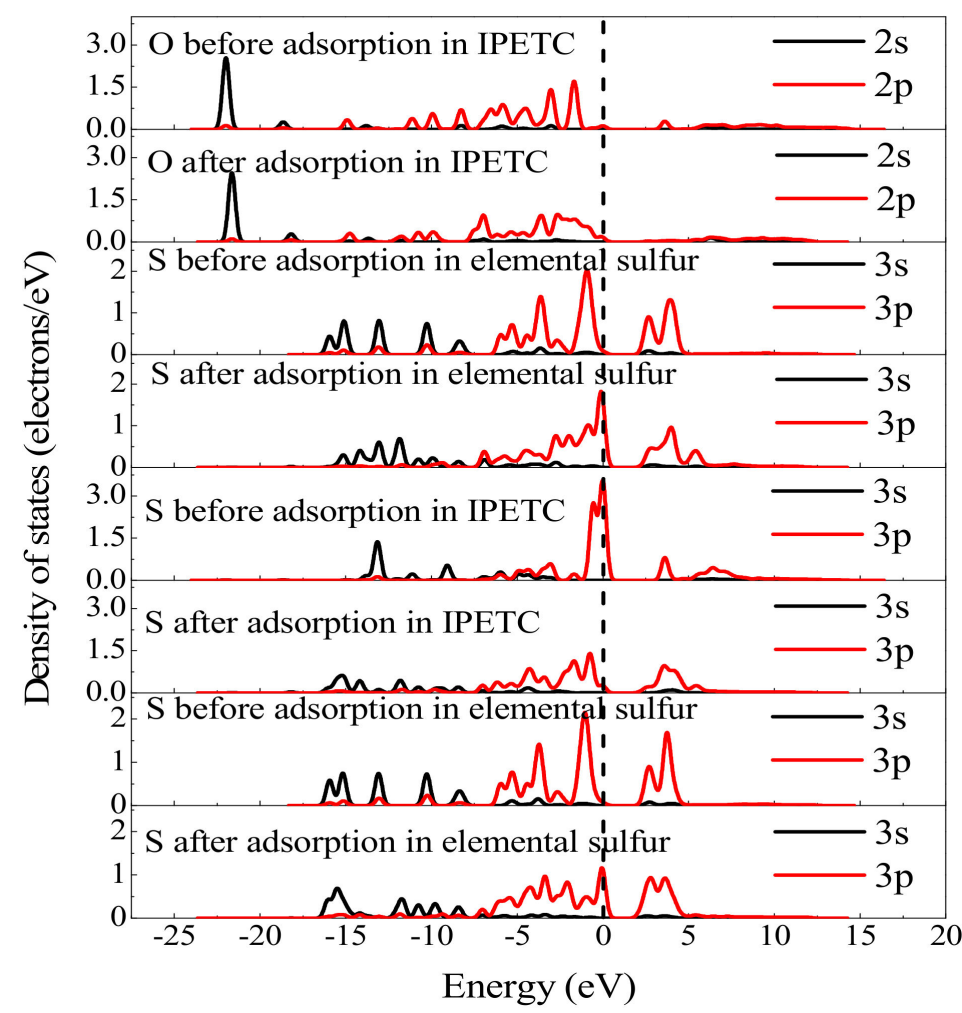

Figure 11. Densities of states of bonding atoms before and after IPETC adsorption on elemental sulfur (100) plane.

The $2 p$ state of $O$ atom of IPETC slightly shifts to the higher energy direction, which means that it gets some electrons in the reaction. However, there is no evident variation in the $3 p$ state of bonding $S$ atom on elemental sulfur surface, indicating that the interaction between $\mathrm{O}$ and $\mathrm{S}$ atoms is weak. The $3 p$ state of carbonyl $\mathrm{S}$ atom of IPETC moves towards the lower energy direction, which indicates that when the $S$ atom of IPETC reacts with an $S$ atom on elemental sulfur surface, it loses some electrons and its oxidation is strengthened. 
At the same time, the localization of $3 p$ state of bonding $S$ atom on elemental sulfur surface declines and evident hybridization happens on the $3 p$ orbital of carbonyl $S$ atom and $3 p$ orbital of $\mathrm{S}$ atom from $-5 \mathrm{eV}$ to $0 \mathrm{eV}$. Thus, the interaction between carbonyl $\mathrm{S}$ atom in IPETC and $S$ atom in elemental sulfur surface is strong.

Based on the above results, it can be concluded that when IPETC interacts with elemental sulfur surface, carbonyl S of IPETC offers some electrons to the $\mathrm{S}$ atom on mineral surface to form a normal covalent bond, while O of IPETC accepts some electrons from the $\mathrm{S}$ atom to generate a backdonation covalent bond. The backdonation covalent bond is relatively weak, and thus a normal covalent bond plays a leading role.

\subsubsection{FTIR Spectrum Analysis}

The infrared spectra of IPETC, elemental sulfur and IPETC-adsorbed elemental sulfur are presented in Figure 12. After interaction with IPETC, the infrared spectrum of elemental sulfur changed significantly, suggesting that IPETC chemisorbed on elemental sulfur surface. Two new strong absorption peaks occurred at $2318.44 \mathrm{~cm}^{-1}$ and $503.42 \mathrm{~cm}^{-1}$, which are separately attributed to $\mathrm{C}=\mathrm{S}-\mathrm{S}$ and $\mathrm{C}-\mathrm{O}-\mathrm{S}$ coupled vibrations. The possible reason for this may be that when IPETC reacted with elemental sulfur, the $S$ and $O$ atoms of $C=S$ and $\mathrm{C}-\mathrm{O}$ bonds separately lost and obtained some electrons. As a result of this, a normal covalent bond and a backdonation covalent bond were formed between $\mathrm{C}=\mathrm{S}$ and $\mathrm{C}-\mathrm{O}$ bonds in IPETC and $S$ atoms in elemental sulfur surface, resulting in the generation of two new coupled vibration peaks.

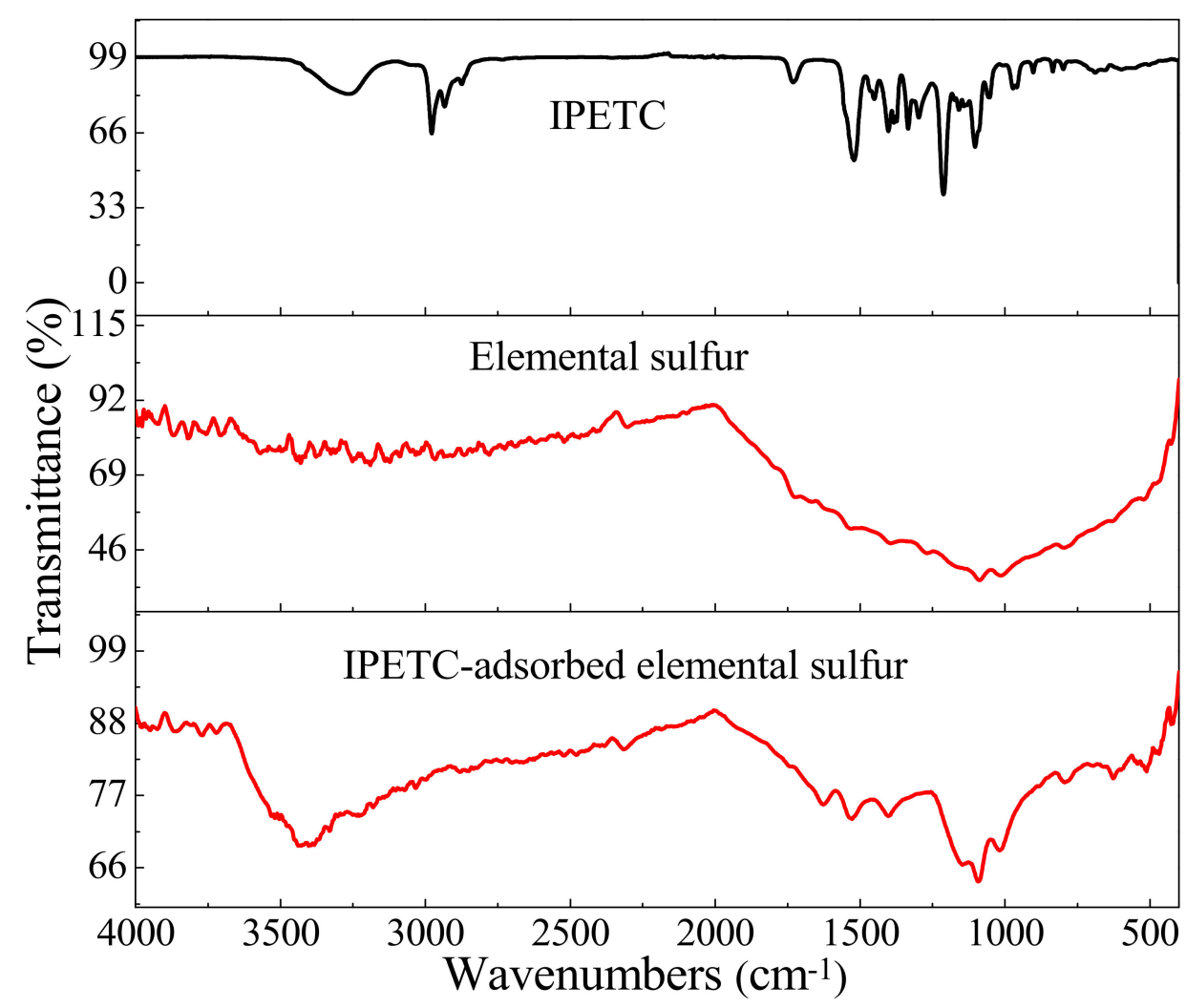

Figure 12. FTIR spectra of IPETC, elemental sulfur and IPETC-adsorbed elemental sulfur.

\section{Conclusions}

In this research, O-Isopropyl-N-Ethyl thionocarbamate (IPETC) collector was used to selectively recover elemental sulfur from a high-sulfur residue. The raw ore flotation test showed that in comparison with sodium ethyl xanthate (SEX) and ammonium dibutyl dithiophosphate (ADDTP) collectors, IPETC exhibited a superior collecting ability and selectivity to the elemental sulfur. Pure mineral flotation and adsorption experiments 
further proved that the collecting power and selectivity of IPETC to elemental sulfur are the optimum among the three collectors.

The bond length of $\mathrm{C}=\mathrm{S} / \mathrm{P}=\mathrm{S}$ covalent bond, Mulliken population and frontier orbital energy difference between collectors and minerals manifested that the selectivity of three collectors to elemental sulfur is in the order of IPETC $>$ ADDTP $>$ SEX. The density of states and frontier orbital analyses showed that the HOMO of each collector is mainly constituted by electron orbitals of carbonyl S atom, the LUMOs of IPETC and SEX are comprised of conjugated big $\pi$-bond formed by electron orbitals of the coplanar functional groups, and the LUMO of ADDTP is composed of the electron orbitals of $\mathrm{O}, \mathrm{S}$ and $\mathrm{P}$ atoms.

The adsorption configuration analysis indicated that the steadiest adsorption configuration of IPETC on the surfaces of elemental sulfur, chalcopyrite, sphalerite, pyrite, anglesite and albite is the simultaneous adsorption of carbonyl $\mathrm{S}$ together with $\mathrm{O}$, and IPETC adsorption on elemental sulfur surface is the most stable. The Mulliken population and density of state analyses of bonding atoms indicated that when IPETC reacts with the elemental sulfur surface, the $3 p$ orbital of carbonyl $S$ atom of IPETC donates electrons to the $3 p$ orbital of $S$ atom in elemental sulfur surface to form normal covalent bond while the $2 p$ orbital of $\mathrm{O}$ atom of IPETC obtains the electrons from the $3 p$ orbital of $S$ atom in elemental sulfur surface to generate a backdonation covalent bond, and the stronger normal covalent bond plays a dominant role. The FTIR spectrum analysis supported the generation of a normal covalent bond and a backdonation covalent bond during IPETC adsorption on elemental sulfur surface.

Author Contributions: Conceptualization, Z.D. and B.X.; methodology, G.L. and B.Z.; software, F.Z.; validation, T.J.; formal analysis, F.W.; investigation, G.L.; resources, G.L.; data curation, Z.D.; writingoriginal draft preparation, G.L. and Z.D.; writing-review and editing, Z.D. and B.X.; supervision, B.X. and T.J.; funding acquisition, G.L. All authors have read and agreed to the published version of the manuscript.

Funding: This research was funded by National Key Research and Development Program of China (Nos. 2018YFC1902005 and 2018YFC1902006).

Institutional Review Board Statement: Not applicable.

Informed Consent Statement: Not applicable.

Data Availability Statement: Data available in a publicly accessible repository.

Conflicts of Interest: The authors declare no conflict of interest.

\section{References}

1. Abbasi, A.; Nasef, M.M.; Yahya, W.Z.N. Sulfur based polymers by inverse vulcanization: A novel path to foster green chemistry. Green Mater. 2020, 8, 172-180. [CrossRef]

2. Dong, Z.L.; Jiang, T.; Xu, B.; Yang, Y.B.; Li, Q. Recovery of gold from pregnant thiosulfate solutions by the resin adsorption technique. Metals 2017, 7, 555. [CrossRef]

3. Dong, Z.L.; Jiang, T.; Xu, B.; Yang, Y.B.; Li, Q. An eco-friendly and efficient process of low potential thiosulfate leaching-resin adsorption recovery for extracting gold from a roasted gold concentrate. J. Clean. Prod. 2019, 229, 387-398. [CrossRef]

4. Dong, Z.L.; Jiang, T.; Xu, B.; Yang, J.K.; Chen, Y.Z.; Yang, Y.B.; Li, Q. Comprehensive recoveries of selenium, copper, gold, silver and lead from a copper anode slime with a clean and economical hydrometallurgical process. Chem. Eng. J. 2020, $393,124762$. [CrossRef]

5. Xu, B.; Kong, W.H.; Li, Q.; Yang, Y.B.; Jiang, T. A review of thiosulfate leaching of gold: Focus on thiosulfate consumption and gold recovery from pregnant solution. Metals 2017, 7, 222. [CrossRef]

6. Xu, B.; Li, K.; Dong, Z.L.; Yang, Y.B.; Li, Q.; Liu, X.L.; Jiang, T. Eco-friendly and economical gold extraction by nickel catalyzed ammoniacal thiosulfate leaching-resin adsorption recovery. J. Clean. Prod. 2019, 233, 1475-1485. [CrossRef]

7. Xu, B.; Chen, Y.Z.; Dong, Z.L.; Jiang, T.; Zhang, B.S.; Liu, G.Q.; Yang, J.K.; Li, Q.; Yang, Y.B. Eco-friendly and efficient extraction of valuable elements from copper anode mud using an integrated pyro-hydrometallurgical process. Resour. Conserv. Recycl. 2021, 164, 105195. [CrossRef]

8. Gu, Y.; Zhang, T.A.; Liu, Y.; Mu, W.Z.; Zhang, W.G.; Dou, Z.H.; Jiang, X.L. Pressure acid leaching of zinc sulfide concentrate. Trans. Nonferr. Met. Soc. China 2010, 20, s136-s140. [CrossRef] 
9. Padilla, R.; Vega, D.; Ruiz, M.C. Pressure leaching of sulfidized chalcopyrite in sulfuric acid-oxygen media. Hydrometallurgy 2010, 86, 80-88. [CrossRef]

10. Jorjani, E.; Ghahreman, A. Challenges with elemental sulfur removal during the leaching of copper and zinc sulfides, and from the residues; a review. Hydrometallurgy 2017, 171, 333-343. [CrossRef]

11. Forward, F.A.; Veltman, H. Direct leaching zinc-sulfide concentrates by Sherritt Gordon. JOM 1959, 11, 836-840. [CrossRef]

12. Corriou, J.P.; Gély, R.; Viers, P. Thermodynamic and kinetic study of the pressure leaching of zinc sulfide in aqueous sulfuric acid. Hydrometallurgy 1988, 21, 85-102. [CrossRef]

13. Lampinen, M.; Laari, A.; Turunen, I. Kinetic model for direct leaching of zinc sulfide concentrates at high slurry and solute concentration. Hydrometallurgy 2015, 153, 160-169. [CrossRef]

14. Mu, W.Z.; Zhang, T.A.; Liu, Y.; Gu, Y.; Dou, Z.H.; Lv, G.Z.; Bao, L.; Zhang, W.G. E-pH diagram of ZnS-H2O system during high pressure leaching of zinc sulfide. Hydrometallurgy 2010, 20, 2012-2019. [CrossRef]

15. Liu, G.Q.; Jiang, K.X.; Zhang, B.S.; Dong, Z.L.; Zhang, F.; Wang, F.; Jiang, T.; Xu, B. Selective flotation of elemental sulfur from pressure acid leaching residue of zinc sulfide. Minerals 2021, 11, 89. [CrossRef]

16. Qin, S.C.; Jiang, K.X.; Wang, H.B.; Zhang, B.S.; Wang, Y.F.; Zhang, X.D. Research on behavior of iron in the zinc sulfide pressure leaching process. Minerals 2020, 10, 224. [CrossRef]

17. Rao, S.; Wang, D.X.; Liu, Z.Q.; Zhang, K.F.; Cao, H.Y.; Tao, J.Z. Selective extraction of zinc, gallium, and germanium from zinc refinery residue using two stage acid and alkaline leaching. Hydrometallurgy 2019, 183, 38-44. [CrossRef]

18. Wang, Z.Y.; Cai, X.L.; Zhang, Z.B.; Zhang, L.B.; Wang, S.X.; Peng, J.H. Separation and enrichment of elemental sulfur and mercury from hydrometallurgical zinc residue using sodium sulfide. Trans. Nonferr. Met. Soc. China 2015, 25, 640-646. [CrossRef]

19. Halfyard, J.E.; Hawboldt, K. Separation of elemental sulfur from hydrometallurgical residue: A review. Hydrometallurgy 2011, 109, 80-89. [CrossRef]

20. Li, H.L.; Yao, X.L.; Wang, M.X.; Wu, S.K.; Ma, W.W.; Wei, W.W.; Li, L.Q. Recovery of elemental sulfur from zinc concentrate direct leaching residue using atmospheric distillation: A pilot-scale experimental study. J. Air Waste Manag. 2014, 64, 95-103. [CrossRef]

21. Li, H.L.; Wu, X.Y.; Wang, M.X.; Wang, J.; Wu, S.K.; Yao, X.L.; Li, L.Q. Separation of elemental sulfur from zinc concentrate direct leaching residue by vacuum distillation. Sep. Purif. Technol. 2014, 138, 41-46. [CrossRef]

22. Chen, J.H.; Lan, L.H.; Chen, Y. Computational simulation of adsorption and thermodynamic study of xanthate, dithiophosphate and dithiocarbamate on galena and pyrite surfaces. Miner. Eng. 2013, 46-47, 136-143. [CrossRef]

23. Huang, Z.Q.; Zhong, H.; Wang, S.; Xia, L.Y.; Zou, W.B.; Liu, G.Y. Investigations on reverse cationic flotation of iron ore by using a Gemini surfactant: Ethane-1,2-bis (dimethyl-dodecyl-ammonium bromide). Chem. Eng. J. 2014, 257, 218-228. [CrossRef]

24. Ma, X.; Xia, L.Y.; Wang, S.; Zhong, H.; Jia, H. Structural modification of xanthate collectors to enhance the flotation selectivity of chalcopyrite. Ind. Eng. Chem. Res. 2017, 56, 6307-6316. [CrossRef]

25. Wang, Z.; Xu, L.H.; Wang, J.M.; Wang, L.; Xiao, J.H. A comparison study of adsorption of benzohydroxamic acid and amyl xanthate on smithsonite with dodecylamine as co-collector. Appl. Surf. Sci. 2017, 426, 1141-1147. [CrossRef]

26. Liu, F.P.; Wang, J.L.; Peng, C.; Liu, Z.H.; Wilson, B.P.; Lundström, M. Recovery and separation of silver and mercury from hazardous zinc refinery residues produced by zinc oxygen pressure leaching. Hydrometallurgy 2019, 185, 38-45. [CrossRef]

27. Fan, Y.Y.; Liu, Y.; Niu, L.P.; Jing, T.L.; Zhang, T.A. Separation and purification of elemental sulfur from sphalerite concentrate direct leaching residue by liquid paraffin. Hydrometallurgy 2019, 186, 162-169. [CrossRef]

28. Xing, P.; Ma, B.Z.; Wang, C.Y.; Wang, L.; Chen, Y.Q. A simple and effective process for recycling zinc-rich paint residue. Waste Manag. 2018, 76, 234-241. [CrossRef]

29. Qiu, T.S.; He, Y.Q.; Qiu, X.H.; Yang, X.L. Density functional theory and experimental studies of $\mathrm{Cu}^{2+}$ activation on a cyanideleached sphalerite surface. J. Ind. Eng. Chem. 2017, 45, 307-315. [CrossRef]

30. Rashchi, F.; Dashti, A.; Arabpour-Yazdi, M.; Abdizadeh, H. Anglesite flotation: A study for lead recovery from zinc leach residue. Miner. Eng. 2005, 18, 205-212. [CrossRef]

31. Dong, Z.L.; Jiang, T.; Xu, B.; Li, Q.; Zhong, H.; Yang, Y.B. Selective flotation of galena using a novel collector S-benzyl-Nethoxycarbonyl thiocarbamate: An experimental and theoretical investigation. J. Mol. Liq. 2021, 330, 115643. [CrossRef]

32. Xu, B.; Wu, J.T.; Dong, Z.L.; Jiang, T.; Li, Q.; Yang, Y.B. Flotation performance, structure-activity relationship and adsorption mechanism of a newly-synthesized collector for copper sulfide minerals in Gacun polymetallic ore. Appl. Surf. Sci. 2021, 551, 149420. [CrossRef]

33. Le, M.N.; Lee, M.S. Hydrometallurgical treatment of elemental sulfur in spent catalysts by aqueous and nonaqueous solutions at low temperature. Miner. Process. Extr. Metall. Rev. 2020, 41, 217-226. [CrossRef]

34. Jia, Y.; Huang, K.H.; Wang, S.; Cao, Z.F.; Zhong, H. The selective flotation behavior and adsorption mechanism of thiohexanamide to chalcopyrite. Miner. Eng. 2019, 137, 187-199. [CrossRef] 